Article

\title{
Applications of Three Dithienylpyrroles-Based Electrochromic Polymers in High-Contrast Electrochromic Devices
}

\author{
Yuh-Shan Su ${ }^{1}$, Jui-Cheng Chang ${ }^{2}$ and Tzi-Yi Wu ${ }^{1, *}$ \\ 1 Department of Chemical and Materials Engineering, National Yunlin University of Science and Technology, \\ Yunlin 64002, Taiwan; d10115003@yuntech.edu.tw \\ 2 Department of Chemical Engineering, National Cheng Kung University, Tainan 70101, Taiwan; \\ d700215@gmail.com \\ * Correspondence: wuty@yuntech.edu.tw; Tel.: +886-5-534-2601 (ext. 4626)
}

Academic Editor: Jodie Lutkenhaus

Received: 3 March 2017; Accepted: 20 March 2017; Published: 22 March 2017

\begin{abstract}
Three dithienylpyrroles (1-(4-(methylthio)phenyl)-2,5-di(thiophen-2-yl)-pyrrole (MPS), 1-(4-methoxyphenyl)-2,5-di(thiophen-2-yl)-pyrrole (MPO), and 4-(2,5-di(thiophen-2-yl)-pyrrol-1-yl) benzonitrile (ANIL)) were synthesized and their corresponding polydithienylpyrroles (PSNS) were electrosynthesized using electrochemical polymerization. Spectroelectrochemical studies indicated that poly(1-(4-(methylthio)phenyl)-2,5-di(thiophen-2-yl)-pyrrole) (PMPS) film was green, dark green, and brown in the neutral, oxidation, and highly oxidized state, respectively. The incorporation of a MPS unit into the PSNS backbone gave rise to a darker color than those of the MPO and ANIL units in the highly oxidized state. The PMPS film showed higher $\Delta T_{\max }(54.47 \%$ at $940 \mathrm{~nm})$ than those of the PMPO (43.87\% at $890 \mathrm{~nm})$ and PANIL $(44.63 \%$ at $950 \mathrm{~nm})$ films in an ionic liquid solution. Electrochromic devices (ECDs) employing PMPS, PMPO, and PANIL as anodic layers and poly(3,4-(2,2-diethypropylenedioxy)thiophene)(PProDOT-Et $\left.{ }_{2}\right)$ as a cathodic layer were constructed. PMPO/PProDOT-Et $t_{2}$ ECD showed the highest $\Delta T_{\max }(41.13 \%)$ and coloration efficiency $\left(674.67 \mathrm{~cm}^{2} \cdot \mathrm{C}^{-1}\right)$ at $626 \mathrm{~nm}$, whereas PMPS/PProDOT-Et ${ }_{2}$ ECD displayed satisfactory $\Delta T_{\max }$ $(32.51 \%)$ and coloration efficiency $\left(637.25 \mathrm{~cm}^{2} \cdot \mathrm{C}^{-1}\right)$ at $590 \mathrm{~nm}$. Repeated cyclic voltammograms of

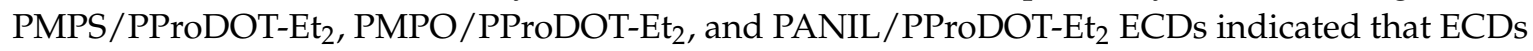
had satisfactory redox stability.
\end{abstract}

Keywords: electrochemical polymerization; optical contrast; spectroelectrochemistry; coloration efficiency; electrochromic devices

\section{Introduction}

$\pi$-conjugated polymers have drawn great attention from researchers in recent years due to their wide use in academic and industrial applications, such as electrochromic devices (ECD) [1-3], thin-film polymer solar cells [4], sensing materials [5,6], polymeric memory devices $[7,8]$, catalysts for methanol and ethanol oxidation reactions [9-11], polymeric light-emitting diodes [12,13], and smart windows [14]. Among them, the benefit of ECDs is their very low power consumption. Moreover, the redox state of ECDs exists with almost no input of power upon changing color, which is called a "memory effect". Two types of electrochromic materials are currently used in ECDs: inorganic electrochromic materials (transition metal oxides) and organic electrochromic materials (viologens, conducting $\pi$-conjugated polymers, metallopolymers, and metallophthalocyanines) [15]. Compared to transition metal oxides, $\pi$-conjugated polymers display satisfactory long-term stability, high optical contrast, high coloration efficiency, and a wide range of colors. In the past decade, the 
most commonly studied $\pi$-conjugated polymers have been polypyrroles [16], polythiophenes [17,18], polyanilines [19], and polycarbazoles [20,21]. In recent years, Toppare and Cihaner et al. reported a series of dithienylpyrrole (SNS) derivatives and investigated their electro-optical properties and electrochromic behaviors [22,23]. The incorporation of a pyrrole ring between two thiophene units increases the electron donating ability of the polymer backbone and decreases the onset potential of polymer films.

Up to now, the incorporation of a 4-(methylthio)aniline unit into a poly(dithienylpyrrole) backbone and the comparison of its effects with alkoxy-phenyl and cyano-phenyl substituents on the electrochromic, spectroelectrochemical, and ECD properties has not been reported. The purpose of this paper is to synthesize a thiomethylphenyl-based anodic polymer (PMPS) via electrochemical polymerizations and compare its spectroelectrochemical properties, coloration efficiency, electrochromic switching, and colorimetry with PMPO and PANIL. Moreover, the benefits of ionic liquids (ILs) such as non-volatility, high conductivity, and a wide potential window make them easy alternatives as stable electrolytes in electrochemical devices [24-28]. In this paper, ECDs were prepared using PMPS, PMPO, and PANIL as the electrochromic materials of anodic electrodes, PProDOT-Et ${ }_{2}$ as the electrochromic material of the cathodic electrode, and an ionic liquid/polymer composite membrane as the electrochromic electrolyte. The spectroelectrochemistry, electrochromic switching, colorimetry, coloration efficiency, open circuit memory, and redox stability

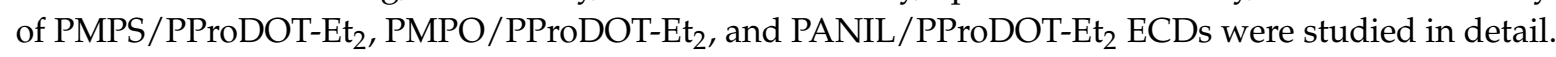

\section{Materials and Methods}

\subsection{Materials and Electrochemical Synthesis}

All chemicals and reagents in this paper were purchased from Acros (Morris Plains, NJ, USA), TCI (Tokyo, Japan), and Sigma-Aldrich (St. Louis, MO, USA), and were used as received. 3,3-diethyl-3,4-dihydro-2H-thieno [3,4-b][1,4] dioxepine (ProDOT-Et 2 ), 1-ethyl-3-propylimidazolium bis(trifluoromethanesulfonyl)imide ([EPI $]\left[\mathrm{TFSI}^{-}\right]$), and 1,4-di(2-thienyl)-1,4-butanedione were synthesized from previously published procedures [29-31]. PMPS, PMPO, and PANIL films were prepared potentiostatically at $0.9 \mathrm{~V}$ on Indium Tin Oxide (ITO) glass electrodes with a charge density of $20 \mathrm{mC} \cdot \mathrm{cm}^{-2}$. PVdF-HFP/ionic liquid composite electrolytes were prepared according to previously published work [32].

\subsubsection{Synthesis of 1-(4-(Methylthio)phenyl)-2,5-di(thiophen-2-yl)-pyrrole (MPS)}

1,4-di(2-thienyl)-1,4-butanedione (1.25 g, $5 \mathrm{mmol})$, 4-(methylthio)aniline (1.06 g, $7 \mathrm{mmol})$, p-toluenesulfonic acid $(0.1 \mathrm{~g}, 0.58 \mathrm{mmol})$, and $25 \mathrm{~mL}$ toluene were added in a round bottom flask and stirred at $110^{\circ} \mathrm{C}$ under Argon for $24 \mathrm{~h}$. After cooling, toluene was evaporated and the crude product was purified using column chromatography (silica gel, dichloromethane: hexane $=1: 1$ ) to give the desired MPS. Yield: $61 \% .{ }^{1} \mathrm{H}$ NMR $\left(700 \mathrm{MHz}\right.$, DMSO- $\left.d_{6}\right): 87.34(\mathrm{~d}, J=8.7 \mathrm{~Hz}, 2 \mathrm{H}$, phenyl-H), 7.31 $(\mathrm{dd}, J=5.2$ and $1.4 \mathrm{~Hz}, 2 \mathrm{H}, \mathrm{Th}-\mathrm{H}), 7.28(\mathrm{~d}, J=8.7 \mathrm{~Hz}, 2 \mathrm{H}$, phenyl-H), $6.90(\mathrm{dd}, J=5.2$ and $3.7 \mathrm{~Hz}, 2 \mathrm{H}$, Th-H), $6.71(\mathrm{dd}, J=3.7$ and $1.4 \mathrm{~Hz}, 2 \mathrm{H}, \mathrm{Th}-\mathrm{H}), 6.56-6.57(\mathrm{~m}, 2 \mathrm{H}, \mathrm{Py}-\mathrm{H}), 2.52\left(\mathrm{~s}, 3 \mathrm{H},-\mathrm{SCH}_{3}\right)$. Elemental analysis: Calculated (Elem. Anal. Calcd.) for $\mathrm{C}_{19} \mathrm{H}_{15} \mathrm{NS}_{3}$ : C, 64.55\%; $\mathrm{H}, 4.28 \%$;, $3.96 \%$. Found: $\mathrm{C}$, $64.35 \% ; \mathrm{H}, 4.22 \%$; N, 3.85\%. The synthetic routes of MPS are shown in Figure 1.

\subsubsection{Synthesis of 1-(4-Methoxyphenyl)-2,5-di(thiophen-2-yl)-pyrrole (MPO)}

MPO was synthesized using a similar procedure to that of MPS. Yield: $65 \% .{ }^{1} \mathrm{H}$ NMR $(700 \mathrm{MHz}$, DMSO- $\left.d_{6}\right): \delta 7.28(\mathrm{dd}, J=3.7$ and $1.4 \mathrm{~Hz}, 2 \mathrm{H}, \mathrm{Th}-\mathrm{H}), 7.27(\mathrm{~d}, J=8.5 \mathrm{~Hz}, 2 \mathrm{H}$, phenyl-H), $7.04(\mathrm{~d}, J=8.5 \mathrm{~Hz}$, $2 \mathrm{H}$, phenyl-H), $6.88(\mathrm{dd}, J=5.1$ and $3.7 \mathrm{~Hz}, 2 \mathrm{H}, \mathrm{Th}-\mathrm{H}), 6.71(\mathrm{dd}, J=3.7$ and $1.4 \mathrm{~Hz}, 2 \mathrm{H}, \mathrm{Th}-\mathrm{H}), 6.55-6.56$ (m, $2 \mathrm{H}, \mathrm{Py}-\mathrm{H}), 3.83\left(\mathrm{~s}, 3 \mathrm{H},-\mathrm{OCH}_{3}\right)$. Elem. Anal. Calcd. for $\mathrm{C}_{19} \mathrm{H}_{15} \mathrm{NOS}_{2}: \mathrm{C}, 67.62 \% ; \mathrm{H}, 4.48 \%$; , $4.15 \%$. Found: C, $67.55 \% ; \mathrm{H}, 4.39 \%$; N, $4.06 \%$. 


\subsubsection{Synthesis of 4-(2,5-Di(thiophen-2-yl)-pyrrol-1-yl)benzonitrile (ANIL)}

ANIL was synthesized using a similar procedure to that of MPS and MPO. Yield: $58 \% .{ }^{1} \mathrm{H}$ NMR (700 MHz, DMSO- $\left.d_{6}\right): \delta 7.98(\mathrm{~d}, J=8.4 \mathrm{~Hz}, 2 \mathrm{H}$, phenyl-H), $7.57(\mathrm{~d}, J=8.4 \mathrm{~Hz}, 2 \mathrm{H}$, phenyl-H), $7.36(\mathrm{dd}$, $J=5.2$ and $1.2 \mathrm{~Hz}, 2 \mathrm{H}, \mathrm{Th}-\mathrm{H}), 6.91(\mathrm{dd}, J=5.2$ and $3.4 \mathrm{~Hz}, 2 \mathrm{H}, \mathrm{Th}-\mathrm{H}), 6.67(\mathrm{dd}, J=3.4$ and $1.2 \mathrm{~Hz}, 2 \mathrm{H}$, Th-H), 6.59-6.60 (m, 2H, Py-H). Elem. Anal. Calcd. for $\mathrm{C}_{19} \mathrm{H}_{12} \mathrm{~N}_{2} \mathrm{~S}_{2}$ : C, 68.64\%; H, 3.64\%; N, 8.43\%. Found: $\mathrm{C}, 68.55 \% ; \mathrm{H}, 3.68 \%$;, $8.27 \%$.

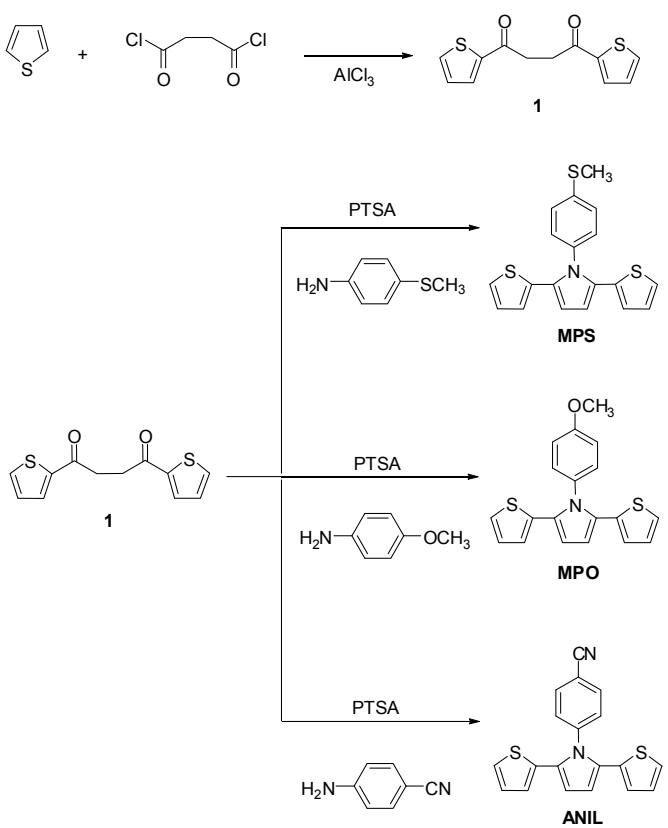

(a)
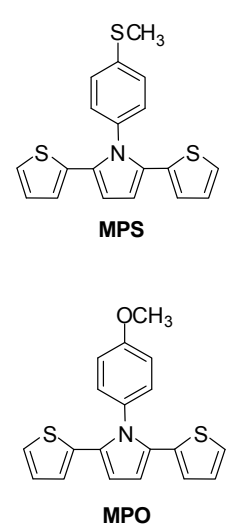

electrochemical polymerization

MPO

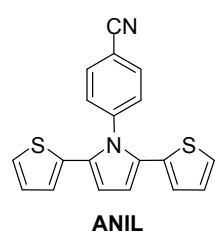

ANIL
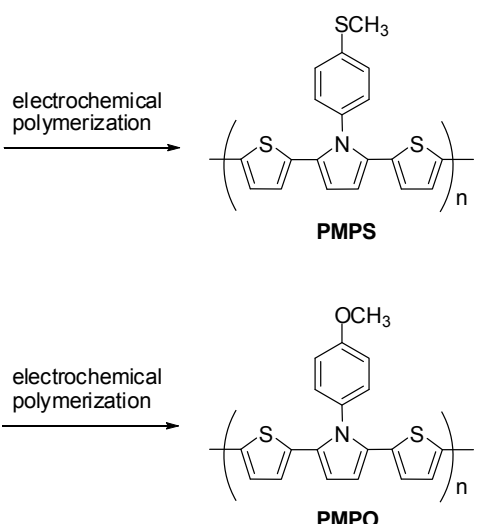

PMPO

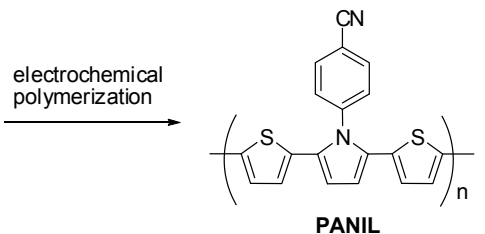

(b)

Figure 1. (a) The synthetic routes of poly(2,5-dithienylpyrrole) derivatives; (b) The electrochemical polymerization of poly(2,5-dithienylpyrrole) derivatives.

\subsection{Construction of ECDs and Spectroelectrochemical Characterizations}

The electrochemical and spectroelectrochemical properties of PMPS, PMPO, and PANIL films coated on the working electrodes and PMPS/PProDOT-Et ${ }_{2}$, PMPO/PProDOT-Et $_{2}$, and PANIL/PProDOT-Et $t_{2}$ ECDs were investigated using a CHI660a electrochemical analyzer $(\mathrm{CH}$ Instruments, Austin, TX, USA) and a V-630 JASCO UV-Visible spectrophotometer (JASCO International Co., Ltd., Tokyo, Japan).

ECDs were built using PMPS, PMPO, or PANIL as the anodically coloring material, PProDOT-Et $_{2}$ as the cathodically coloring material, and PVdF-HFP/ionic liquid composite membranes as electrolytes. PMPS, PMPO, and PANIL films were electrodeposited potentiostatically onto ITO-coated glasses at $+0.9 \mathrm{~V}$, and PProDOT-Et $t_{2}$ were electrodeposited onto ITO-coated glasses at $+1.4 \mathrm{~V}$. Film thicknesses of the deposited anodic and cathodic layers were obtained with an Alpha-Step profilometer (KLA Tencor D-120, KLA-Tencor, Milpitas, CA, USA). The approximate average thicknesses of anodic and cathodic layers are 100-105 nm. ECDs were assembled by anodic and cathodic polymers facing each other and were separated by PVdF-HFP/ionic liquid composite membranes.

\section{Results and Discussion}

\subsection{Electrochemical Polymerizations of Anodic Polymer Films}

The cyclic voltammogram (CV) curves of MPS, MPO, and ANIL in EtOH/EA (1:1, by volume) solution containing $0.1 \mathrm{M} \mathrm{LiClO}_{4}$ are shown in Figure 2, after scanning the potentials between -0.4 
and $1.4 \mathrm{~V}$ at a scan rate of $100 \mathrm{mV} \cdot \mathrm{s}^{-1}$ continuously for 20 cycles. PMPS, PMPO, and PANIL were electrodeposited onto the surface of the ITO working electrode, and the synthetic routes of PMPS, PMPO, and PANIL are displayed in Figure 1. The onset potentials of MPS, MPO, and ANIL are $0.7,0.69$, and $0.81 \mathrm{~V}$, respectively. The onset potential of MPS is comparable to MPO, implying the incorporation of the methylthio-phenyl unit on the nitrogen atom of the pyrrole ring that shows a similar electron donating property to that of the methoxyphenyl unit. However, the incorporation of the benzonitrile unit on the nitrogen atom of the pyrrole ring shows a larger onset potential than those of the methylthio-phenyl and methoxyphenyl units, implying the incorporation of an electron withdrawing benzonitrile unit that increases the onset potential significantly. The oxidation peaks of PMPS, PMPO, and PANIL are located at $0.95,0.9$, and $1.0 \mathrm{~V}$, respectively, whereas the reduction peaks of PMPS, PMPO, and PANIL appear at $0.5,0.55$, and $0.6 \mathrm{~V}$, respectively.

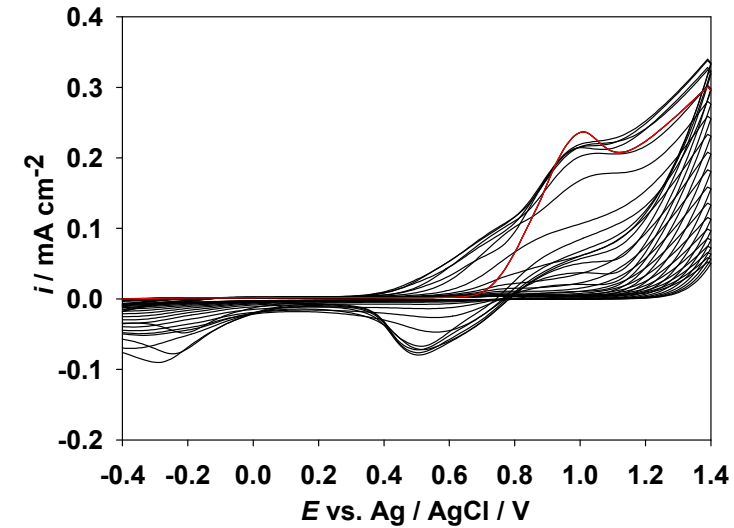

(a)

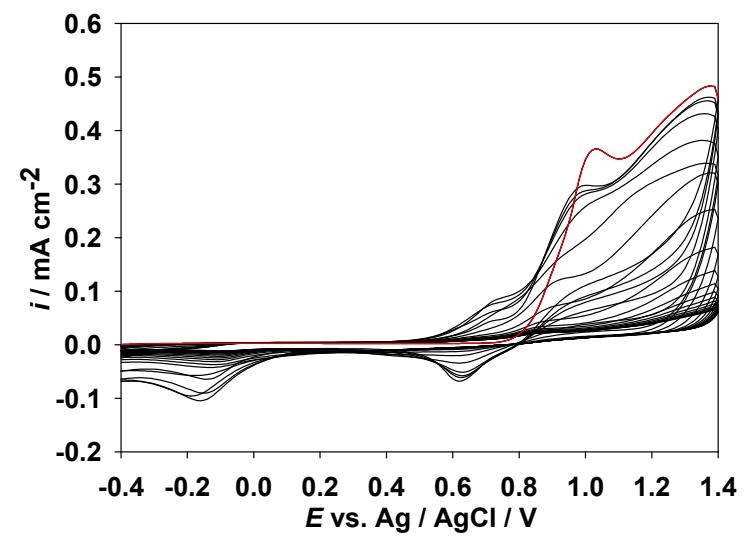

(c)

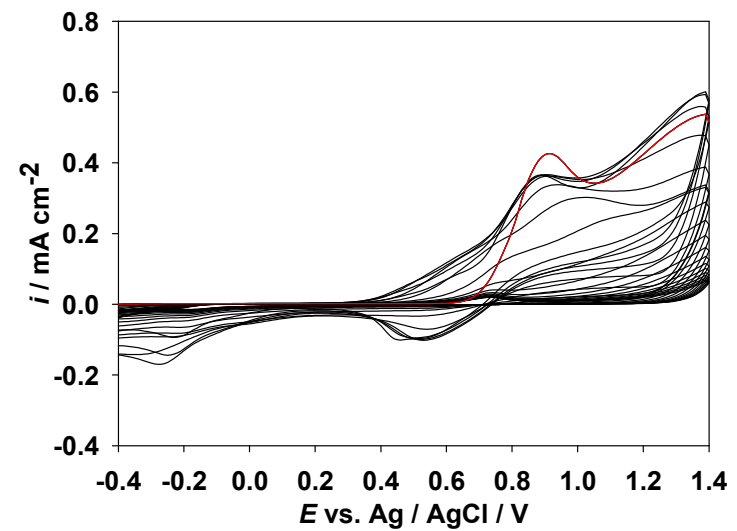

(b)

Figure 2. Cyclic voltammograms of $2 \mathrm{mM}$ (a) MPS; (b) MPO, and (c) ANIL in $0.1 \mathrm{M} \mathrm{LiClO}_{4} / \mathrm{EtOH} / \mathrm{EA}$ at a scan rate of $100 \mathrm{mV} \cdot \mathrm{s}^{-1}$ on an ITO working electrode. The red line indicates the first cycle of CVs.

Figure 3a-c shows the relationship of the peak current vs. scan rate of PMPS, PMPO, and PANIL films in a $0.1 \mathrm{M} \mathrm{LiClO}_{4} / \mathrm{EtOH}$ solution at scanning rates between 25 and $250 \mathrm{mV} \cdot \mathrm{s}^{-1}$. The scan rate dependence of the anodic and cathodic peak current densities shows a linear dependence on the scan rate as depicted in Figure $3 \mathrm{~d}-\mathrm{f}$, indicating that the redox processes are not diffusion controlled and that the electroactive polymer films are well-adhered on the ITO-coated electrode surface [33]. 


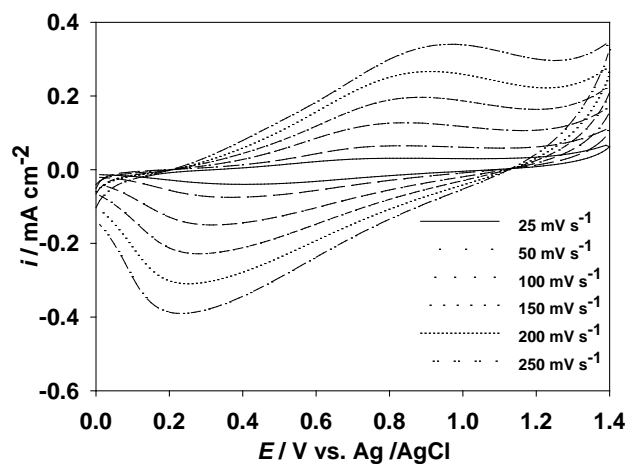

(a)

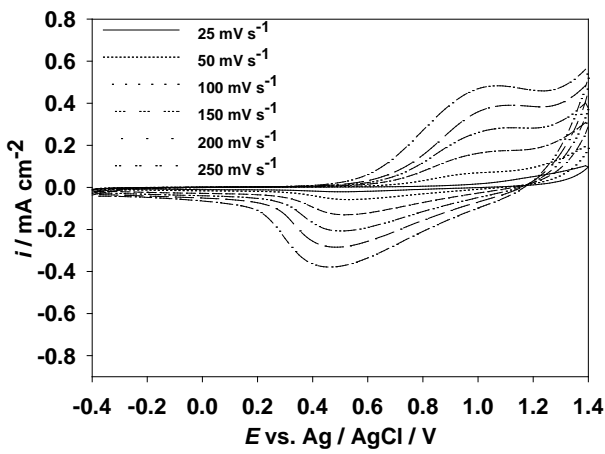

(c)

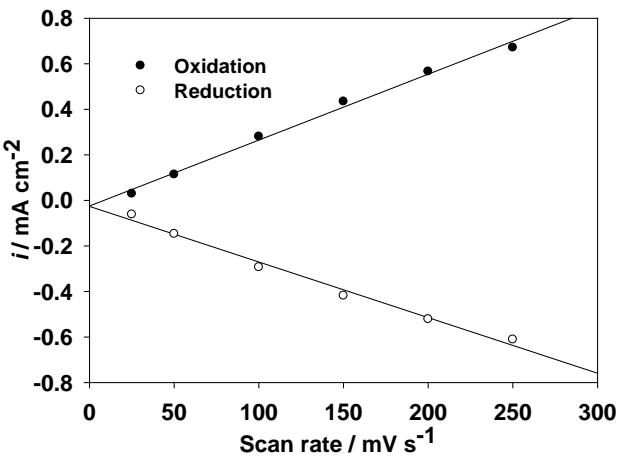

(e)

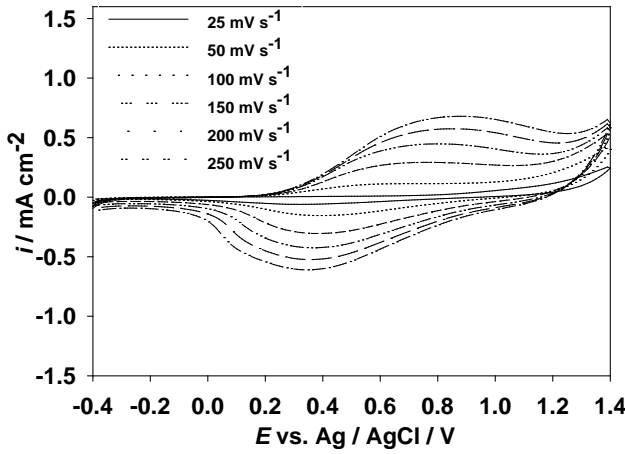

(b)

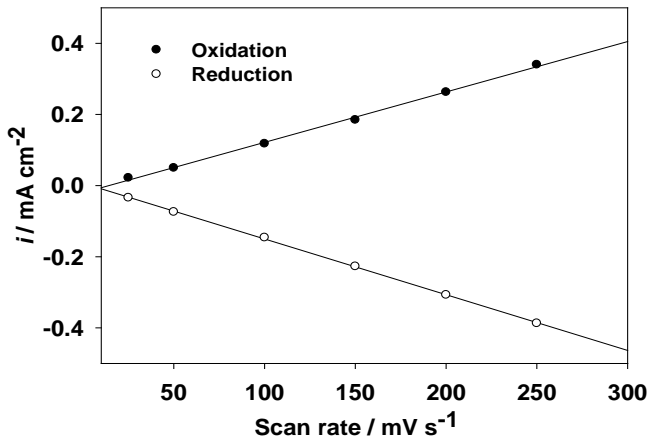

(d)

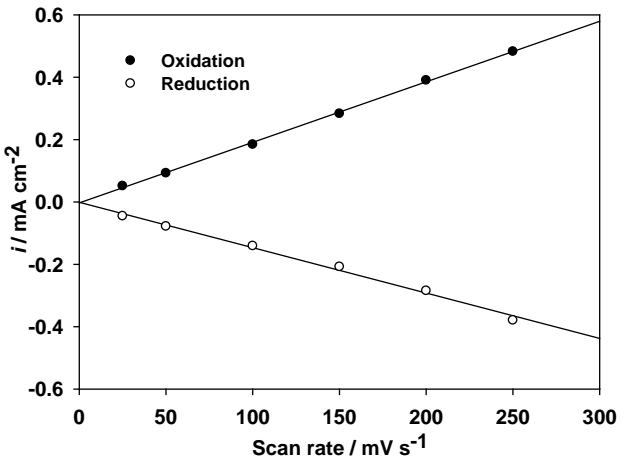

(f)

Figure 3. CV curves of (a) PMPS; (b) PMPO; and (c) PANIL films at different scan rates between 25 and $250 \mathrm{mV} \cdot \mathrm{s}^{-1}$ in $0.1 \mathrm{M} \mathrm{LiClO}_{4} / \mathrm{EtOH}$ solution, and the relationship between the peak current density and scan rate of (d) PMPS; (e) PMPO; and (f) PANIL films in $0.1 \mathrm{M} \mathrm{LiClO}_{4} / \mathrm{EtOH}$ solution.

\subsection{Electrochromic Properties of PMPS, PMPO, and PANIL Films}

The absorption spectra of the PMPS, PMPO, and PANIL films coated on an ITO/glass electrode were investigated between -0.4 and $+1.6 \mathrm{~V}_{\text {in }}\left[\mathrm{EPI}^{+}\right]\left[\mathrm{TFSI}^{-}\right]$solution. As shown in Figure $4 \mathrm{~b}$, the PMPO film shows an evident $\pi-\pi^{*}$ transition peak at around $421 \mathrm{~nm}$. However, the PMPS film shows a shoulder at about $440 \mathrm{~nm}$ (Figure $4 \mathrm{a}$ ); the incorporation of a methylthio group into the polymer backbone causes bathochromic shifts in the absorption band. On the other hand, the incorporation of an electron withdrawing benzonitrile unit into the PSNS backbone deactivates the phenyl unit on the pyrrole ring of PANIL, and the $\pi-\pi^{*}$ transition of the PANIL film in $\left[\mathrm{EPI}^{+}\right]\left[\mathrm{TFSI}^{-}\right]$solution shifts hypsochromically to $360 \mathrm{~nm}$.

Upon applying a potential of $+0.8 \mathrm{~V}$ (vs. $\mathrm{Ag} / \mathrm{AgCl}$ ), the shoulder of the PMPS film at around $440 \mathrm{~nm}$ and the absorption peak of the PANIL film at around $360 \mathrm{~nm}$ decrease gradually, and charge carrier bands emerge at around 600-1000 nm. Table 1 shows the photos of PMPS, PMPO, and PANIL in the $\left[\mathrm{EPI}^{+}\right]\left[\mathrm{TFSI}^{-}\right]$solution at various potentials. The PMPS film was green $(0 \mathrm{~V})$ in the neutral state, 
dark green $(1.2 \mathrm{~V})$ in the oxidation state, and brown $(1.6 \mathrm{~V})$ in the highly oxidized state. The PMPO and PANIL films were light green $(0 \mathrm{~V})$ in their neutral state, whereas the PMPO and PANIL films were blue $(1.6 \mathrm{~V})$ and grey $(1.6 \mathrm{~V})$, respectively, in the highly oxidized state. The incorporation of an MPS unit into the PSNS backbone gives rise to darker color than those of the MPO and ANIL units.

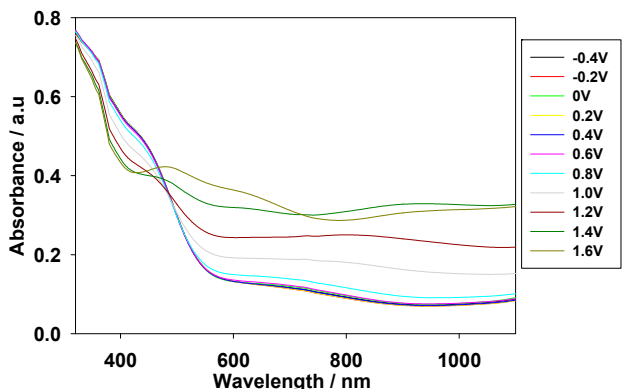

(a)

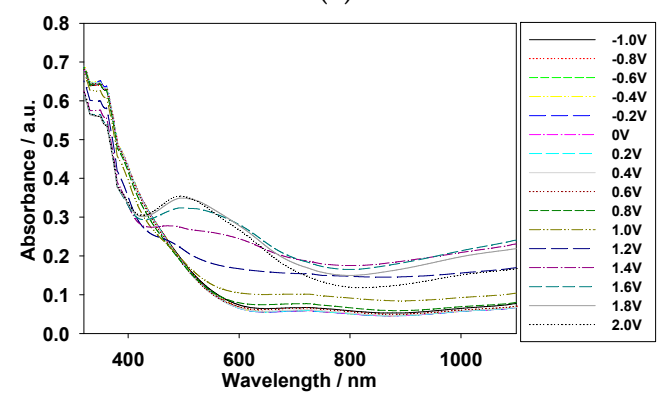

(c)

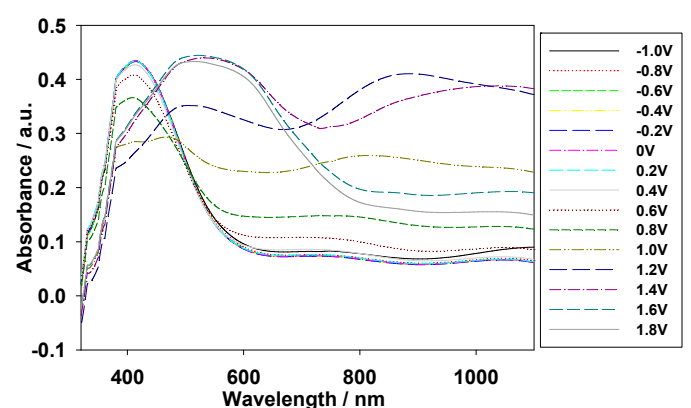

(b)

Figure 4. Spectroelectrochemical spectra of (a) PMPS; (b) PMPO; and (c) PANIL films on an ITO electrode at different potentials in $\left[\mathrm{EPI}^{+}\right]\left[\mathrm{TFSI}^{-}\right]$solution.

Table 1. Electrochromic behaviors of PMPS, PMPO, and PANIL films in $\left[\mathrm{EPI}^{+}\right]\left[\mathrm{TFSI}^{-}\right]$solution at $0 \mathrm{~V}$ and $+1.6 \mathrm{~V}$.

\begin{tabular}{ccc}
\hline Polymer Films and ECDs & Reduction $(\mathbf{0}$ V) & Oxidation $(+\mathbf{1 . 6}$ V) \\
\hline PMPS & & \\
PMPO & & \\
\hline PANIL & & \\
\hline PMPS/PProDOT-Et ${ }_{2}$ & & \\
\hline PMPO/PProDOT-Et & & \\
\hline PANIL/PProDOT-Et & \\
\hline
\end{tabular}


The CIE (Commission Internationale de I'Eclairage) chromaticity diagrams of the PMPS, PMPO, and PANIL films in neutral and oxidation states are shown in Figure 5 , and the colorimetric values $(L$, $a, b, L^{*}, a^{*}$, and $\left.b^{*}\right)$ and CIE chromaticity values $(x, y)$ of the three polymer films at various potentials in the $\left[\mathrm{EPI}^{+}\right]\left[\mathrm{TFSI}^{-}\right]$solution are summarized in Table 2. The $b^{*}$ of the PMPO film was negative between 1.2 and $1.8 \mathrm{~V}$, demonstrating that the PMPO film was blue $(1.6 \mathrm{~V})$ in the highly oxidized state.

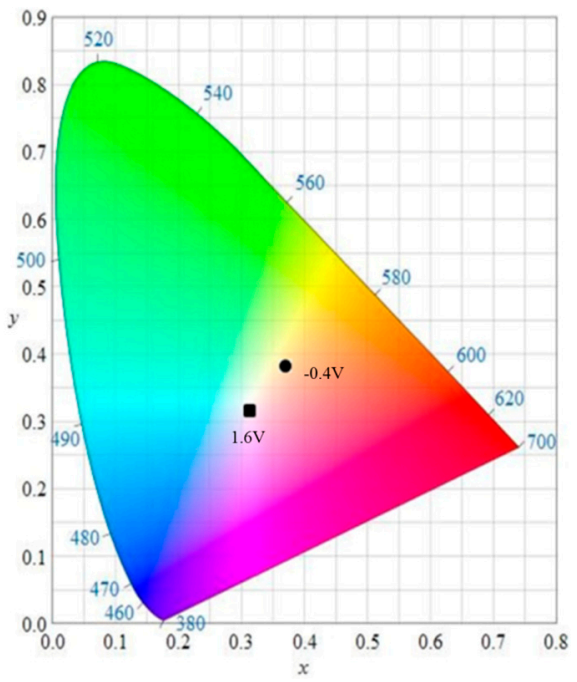

(a)

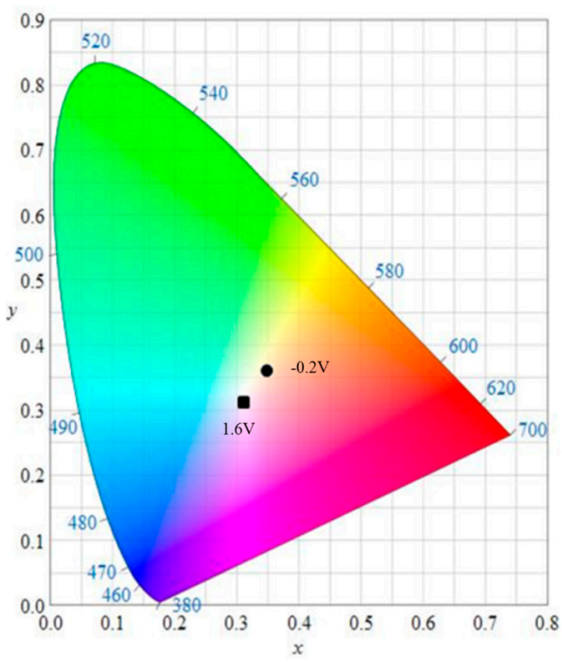

(c)

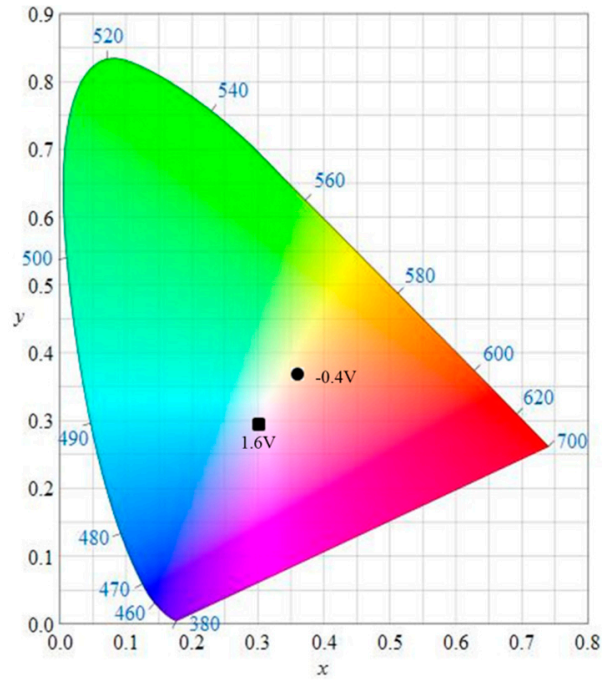

(b)

Figure 5. CIE chromaticity diagrams of (a) PMPS film in $\left[\mathrm{EPI}^{+}\right]\left[\mathrm{TFSI}^{-}\right]$solution at $-0.4 \mathrm{~V}(\bullet)$ and $1.6 \mathrm{~V}(\mathbf{\square})$; (b) PMPO film in $\left[\mathrm{EPI}^{+}\right]\left[\mathrm{TFSI}^{-}\right]$solution at $-0.4 \mathrm{~V}(\bullet)$ and $1.6 \mathrm{~V}(\boldsymbol{\square})$; and (c) PANIL film in $\left[\mathrm{EPI}^{+}\right]\left[\mathrm{TFSI}^{-}\right]$solution at $-0.2 \mathrm{~V}(\bullet)$ and $1.6 \mathrm{~V}$

The optical band gap $\left(E_{\mathrm{g}}\right)$ of PMPS, PMPO, and PANIL can be calculated according to the Planck equation [34],

$$
E_{\mathrm{g}}=1241 / \lambda_{\text {onset }}
$$

where $\lambda_{\text {onset }}$ is the wavelength at which the onset of absorption occurs. The $E_{g}$ of PMPS, PMPO, and PANIL were $2.25,2.17$, and $2.21 \mathrm{eV}$, respectively. 
Table 2. The colorimetric values $\left(L, a, b, L^{*}, a^{*}, b^{*}\right)$ and CIE chromaticity values $(x, y)$ of PMPS, PMPO, and PANIL films at different applied potentials in $\left[\mathrm{EPI}^{+}\right]\left[\mathrm{TFSI}^{-}\right]$.

\begin{tabular}{|c|c|c|c|c|c|c|c|c|c|}
\hline Polymers & $E / \mathrm{V}$ & $L$ & $a$ & $b$ & $L^{*}$ & $a^{*}$ & $b^{*}$ & $x$ & $y$ \\
\hline \multirow[t]{11}{*}{ PMPS } & -0.4 & 80.25 & -1.00 & 25.76 & 84.17 & 0.09 & 31.17 & 0.3726 & 0.3828 \\
\hline & -0.2 & 80.24 & -0.92 & 25.75 & 84.17 & 0.17 & 31.16 & 0.3727 & 0.3827 \\
\hline & 0 & 80.37 & -1.16 & 25.83 & 84.27 & -0.08 & 31.25 & 0.3724 & 0.383 \\
\hline & 0.2 & 80.26 & -0.93 & 25.73 & 84.18 & 0.16 & 31.12 & 0.3726 & 0.3826 \\
\hline & 0.4 & 80.32 & -1.06 & 25.72 & 84.23 & 0.03 & 31.1 & 0.3723 & 0.3826 \\
\hline & 0.6 & 80.19 & -1.35 & 25.35 & 84.13 & -0.28 & 30.55 & 0.3708 & 0.3819 \\
\hline & 0.8 & 79.38 & -1.78 & 23.81 & 83.45 & -0.73 & 28.4 & 0.3663 & 0.3784 \\
\hline & 1.0 & 76.51 & -1.99 & 18.99 & 81.03 & -1.01 & 21.93 & 0.3541 & 0.3666 \\
\hline & 1.2 & 72.95 & -1.61 & 13.51 & 78 & -0.66 & 14.98 & 0.3413 & 0.3526 \\
\hline & 1.4 & 67.69 & -0.39 & 6.78 & 73.42 & 0.57 & 6.93 & 0.3269 & 0.3346 \\
\hline & 1.6 & 64.25 & 1.41 & 3.69 & 70.37 & 2.52 & 3.40 & 0.3227 & 0.3251 \\
\hline \multirow[t]{12}{*}{ PMPO } & -0.4 & 84.19 & 0.76 & 24.26 & 87.42 & 1.91 & 28.09 & 0.3677 & 0.3731 \\
\hline & -0.2 & 84.19 & 0.74 & 24.29 & 87.42 & 1.9 & 28.13 & 0.3678 & 0.3732 \\
\hline & 0 & 84.16 & 0.7 & 24.31 & 87.4 & 1.85 & 28.15 & 0.3677 & 0.3733 \\
\hline & 0.2 & 84.16 & 0.56 & 24.23 & 87.4 & 1.71 & 28.04 & 0.3673 & 0.3733 \\
\hline & 0.4 & 83.98 & -0.05 & 23.49 & 87.25 & 1.1 & 27.01 & 0.3645 & 0.3719 \\
\hline & 0.6 & 83.12 & -0.97 & 21.06 & 86.55 & 0.15 & 23.77 & 0.3571 & 0.3667 \\
\hline & 0.8 & 81 & -1.31 & 16.05 & 84.8 & -0.22 & 17.39 & 0.3447 & 0.3549 \\
\hline & 1.0 & 75.3 & -0.14 & 5.62 & 80.01 & 0.92 & 5.23 & 0.3228 & 0.3296 \\
\hline & 1.2 & 67.81 & 2.85 & -2.19 & 73.53 & 4.07 & -3.2 & 0.31 & 0.3087 \\
\hline & 1.4 & 61.26 & 3.77 & -4.04 & 67.67 & 5.12 & -5.21 & 0.3069 & 0.3024 \\
\hline & 1.6 & 61.06 & 4.08 & -3.24 & 67.49 & 5.46 & -4.36 & 0.3095 & 0.3041 \\
\hline & 1.8 & 61.94 & 4.08 & -2.58 & 68.29 & 5.45 & -3.64 & 0.3113 & 0.306 \\
\hline \multirow[t]{13}{*}{ PANIL } & -0.4 & 87.66 & -0.42 & 20 & 90.25 & 0.76 & 21.69 & 0.3525 & 0.3606 \\
\hline & -0.2 & 87.71 & -0.44 & 20.01 & 90.29 & 0.74 & 21.7 & 0.3525 & 0.3606 \\
\hline & 0 & 87.74 & -0.47 & 20.03 & 90.32 & 0.71 & 21.71 & 0.3525 & 0.3606 \\
\hline & 0.2 & 87.79 & -0.52 & 20.03 & 90.35 & 0.66 & 21.71 & 0.3524 & 0.3606 \\
\hline & 0.4 & 87.78 & -0.64 & 19.96 & 90.35 & 0.55 & 21.62 & 0.352 & 0.3606 \\
\hline & 0.6 & 87.69 & -0.93 & 19.58 & 90.28 & 0.25 & 21.13 & 0.3507 & 0.3599 \\
\hline & 0.8 & 87.11 & -1.29 & 18.28 & 89.81 & -0.11 & 19.55 & 0.3473 & 0.3573 \\
\hline & 1.0 & 85.34 & -1.45 & 15.21 & 88.36 & -0.3 & 15.9 & 0.3406 & 0.3508 \\
\hline & 1.2 & 80.64 & -0.96 & 8.74 & 84.5 & 0.13 & 8.55 & 0.3277 & 0.3365 \\
\hline & 1.4 & 74.34 & 0.8 & 3.1 & 79.19 & 1.9 & 2.44 & 0.3185 & 0.3229 \\
\hline & 1.6 & 70.62 & 3.46 & 1.04 & 75.99 & 4.7 & 0.25 & 0.3186 & 0.3161 \\
\hline & 1.8 & 69.85 & 5.35 & 1.53 & 75.32 & 6.69 & 0.81 & 0.3231 & 0.3158 \\
\hline & 2.0 & 70.35 & 5.88 & 2.85 & 75.76 & 7.24 & 2.26 & 0.3272 & 0.3185 \\
\hline
\end{tabular}

The incorporation of methoxyphenyl into the PSNS backbone showed a lower $E_{\mathrm{g}}$ than those of the methylthio-phenyl and benzonitrile units. The lowest unoccupied molecular orbital (LUMO) and highest occupied molecular orbital (HOMO) energy levels of PMPS, PMPO, and PANIL were determined using cyclic voltammetry. The $E_{\mathrm{HOMO}}$ was calculated from $E_{\text {onset }}$ using the formula [35],

$$
E_{\mathrm{HOMO}}=-\mathrm{e}\left(E_{\text {onset }}+4.8 \mathrm{~V}\right)(\text { vs. vacuum })
$$

where $E_{\text {onset }}$ is the onset potential of oxidation. $E_{\mathrm{LUMO}}$ of the polymers was calculated using the formula,

$$
E_{\mathrm{LUMO}}=E_{\mathrm{HOMO}}+E_{\mathrm{g}}
$$

The HOMO energy level of PMPS, PMPO, and PANIL are $-4.90,-4.88$, and $-5.00 \mathrm{eV}$, respectively, and the LUMO energy level of PMPS, PMPO, and PANIL are $-2.65,-2.71$, and $-2.79 \mathrm{eV}$, respectively. The PANIL film shows a lower LUMO energy level than those of the PMPS and PMPO films, and this can be attributed to the incorporation of an electron withdrawing cyano group in the ANIL unit that decreases the LUMO energy level significantly.

A square-wave cyclic potential step method accompanied by UV-Vis spectroscopy was used to determine the optical contrast and switching time of the PMPS, PMPO, and PANIL films. The polymer films were immersed in $\left[\mathrm{EPI}^{+}\right]\left[\mathrm{TFSI}^{-}\right]$solution and stepped by repeated potential between neutral 
and oxidation states with a time interval of $5 \mathrm{~s}$. Figure 6 exhibits the transmittance-time profiles of the PMPS film at 600 and $940 \mathrm{~nm}$, the PMPO film at 584 and $950 \mathrm{~nm}$, and the PANIL film at 566 and $950 \mathrm{~nm}$. The coloration switching time $\left(\tau_{\mathrm{c}}\right)$ and bleaching switching time $\left(\tau_{\mathrm{b}}\right)$ of the PMPS, PMPO, and PANIL films in the $\left[\mathrm{EPI}^{+}\right]\left[\mathrm{TFSI}^{-}\right]$solution are summarized in Table 3. The optical switching time $\left(T_{95 \%}\right)$ of the PMPS film is 2.21 and $1.97 \mathrm{~s}$ at 600 and $940 \mathrm{~nm}$, respectively, from the bleaching state to the coloring state at the 100th cycle, and 1.93 and $2.01 \mathrm{~s}$ at 600 and $940 \mathrm{~nm}$, respectively, from the coloring state to the bleaching state at the 100th cycle.

Table 3. Color-bleach kinetics of PMPS, PMPO, and PANIL films in $\left[\mathrm{EPI}^{+}\right]\left[\mathrm{TFSI}^{-}\right]$and ECDs.

\begin{tabular}{|c|c|c|c|c|c|c|}
\hline \multirow[t]{2}{*}{ Polymer Films and ECDs } & \multirow[t]{2}{*}{$\lambda_{\max } / \mathrm{nm}$} & \multirow[t]{2}{*}{ Cycle No. } & $\begin{array}{c}\text { Optical } \\
\text { Contrast } / \%\end{array}$ & $\tau_{\mathrm{c}} / \mathrm{s}$ & $\begin{array}{c}\text { Optical } \\
\text { Contrast } / \%\end{array}$ & $\tau_{\mathrm{b}} / \mathrm{s}$ \\
\hline & & & $\Delta T / \%$ & $T_{95 \%}$ & $\Delta T / \%$ & $T_{95 \%}$ \\
\hline \multirow{6}{*}{ PMPS film in $\left[\mathrm{EPI}^{+}\right]\left[\mathrm{TFSI}^{-}\right]$} & \multirow{3}{*}{600} & 1 & 17.59 & 2.22 & 17.59 & 2.01 \\
\hline & & 50 & 17.27 & 2.16 & 17.28 & 2.08 \\
\hline & & 100 & 18.62 & 2.21 & 18.61 & 1.93 \\
\hline & \multirow{3}{*}{940} & 1 & 53.94 & 1.98 & 53.94 & 2.09 \\
\hline & & 50 & 53.1 & 1.96 & 53.1 & 2.07 \\
\hline & & 100 & 54.47 & 1.97 & 54.47 & 2.01 \\
\hline \multirow{6}{*}{ PMPO film in $\left[\mathrm{EPI}^{+}\right]\left[\mathrm{TFSI}^{-}\right]$} & \multirow{3}{*}{584} & 1 & 18.02 & 2.05 & 18.02 & 1.76 \\
\hline & & 50 & 18.01 & 2.04 & 18.03 & 1.69 \\
\hline & & 100 & 16.98 & 1.92 & 16.98 & 1.76 \\
\hline & & 1 & 43.99 & 1.85 & 43.99 & 2.02 \\
\hline & \multirow[t]{2}{*}{890} & 50 & 43.45 & 1.74 & 43.45 & 2.13 \\
\hline & & 100 & 43.72 & 1.87 & 43.87 & 2.01 \\
\hline \multirow{6}{*}{ PANIL film in $\left[\mathrm{EPI}^{+}\right]\left[\mathrm{TFSI}^{-}\right]$} & \multirow{3}{*}{566} & 1 & 15.83 & 2.05 & 15.82 & 2.05 \\
\hline & & 50 & 15.26 & 2.06 & 15.25 & 2.09 \\
\hline & & 100 & 15.09 & 2.01 & 15.09 & 2.08 \\
\hline & \multirow{3}{*}{950} & 1 & 46.17 & 1.97 & 46.17 & 2.10 \\
\hline & & 50 & 44.63 & 1.94 & 44.63 & 2.28 \\
\hline & & 100 & 39.44 & 2.08 & 39.44 & 2.14 \\
\hline \multirow{3}{*}{ PMPS/PProDOT-Et $t_{2}$ ECD } & \multirow{3}{*}{590} & 1 & 32.51 & 1.00 & 32.51 & 1.10 \\
\hline & & 50 & 30.43 & 0.94 & 30.43 & 1.00 \\
\hline & & 100 & 31.92 & 0.99 & 31.91 & 1.01 \\
\hline \multirow{3}{*}{ PMPO/PProDOT-Et ${ }_{2}$ ECD } & \multirow{3}{*}{626} & 1 & 41.13 & 1.54 & 41.13 & 1.10 \\
\hline & & 50 & 39.43 & 1.45 & 39.43 & 0.98 \\
\hline & & 100 & 38.50 & 1.42 & 38.50 & 1.12 \\
\hline \multirow{3}{*}{ PANIL/PProDOT-Et ${ }_{2}$ ECD } & \multirow{3}{*}{628} & 1 & 25.00 & 1.21 & 25.00 & 1.06 \\
\hline & & 50 & 22.23 & 1.14 & 22.23 & 1.03 \\
\hline & & 100 & 21.71 & 1.17 & 21.71 & 1.06 \\
\hline
\end{tabular}

The optical contrast $(\Delta T \%)$ is an important characteristic in electrochromic applications [36]. The $\Delta T_{\max }$ of the PMPS, PMPO, and PANIL films are $18.62 \%, 18.02 \%$, and $15.83 \%$ at $600 \mathrm{~nm}, 584 \mathrm{~nm}$, and $566 \mathrm{~nm}$, respectively, in the [EPI $\left.{ }^{+}\right]\left[\mathrm{TFSI}^{-}\right]$solution. Moreover, The $\Delta T_{\max }$ of the PMPS, PMPO, and PANIL films are $54.47 \%, 43.99 \%$, and $46.17 \%$ at $940 \mathrm{~nm}, 890 \mathrm{~nm}$, and $950 \mathrm{~nm}$, respectively, in the $\left[\mathrm{EPI}^{+}\right]\left[\mathrm{TFSI}^{-}\right]$solution. The PMPS film shows the highest $\Delta T_{\max }(54.47 \%$ at $940 \mathrm{~nm})$ among these polymer films.

The coloration efficiency (CE) is also a useful parameter in electrochromic applications. CE can be calculated using the following equations at a specific wavelength [37]:

$$
\begin{gathered}
\Delta \mathrm{OD}=\log \left(T_{\mathrm{b}} / T_{\mathrm{c}}\right) \\
\eta=\Delta \mathrm{OD} / \mathrm{Q}_{\mathrm{d}}
\end{gathered}
$$

where $\triangle \mathrm{OD}$ represents the variation of the optical density at a specific wavelength. $T_{\mathrm{b}}$ and $T_{\mathrm{c}}$ denote the transmittance of the bleaching state and coloring state, respectively. $C E(\eta)$ stands for the power efficiency of the electrochromic materials and devices. $Q_{\mathrm{d}}\left(\mathrm{mC} \cdot \mathrm{cm}^{-2}\right)$ is the charge density 
of the electrodes. The $\eta_{\max }$ of the PMPS, PMPO, and PANIL films are $298.28 \mathrm{~cm}^{2} \cdot \mathrm{C}^{-1}$ at $940 \mathrm{~nm}$, $142.48 \mathrm{~cm}^{2} \cdot \mathrm{C}^{-1}$ at $890 \mathrm{~nm}$, and $279.19 \mathrm{~cm}^{2} \cdot \mathrm{C}^{-1}$ at $950 \mathrm{~nm}$, respectively.

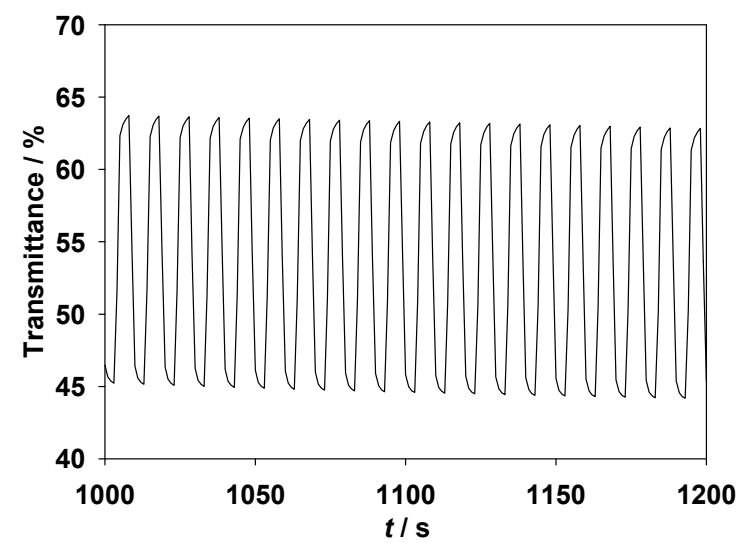

(a)

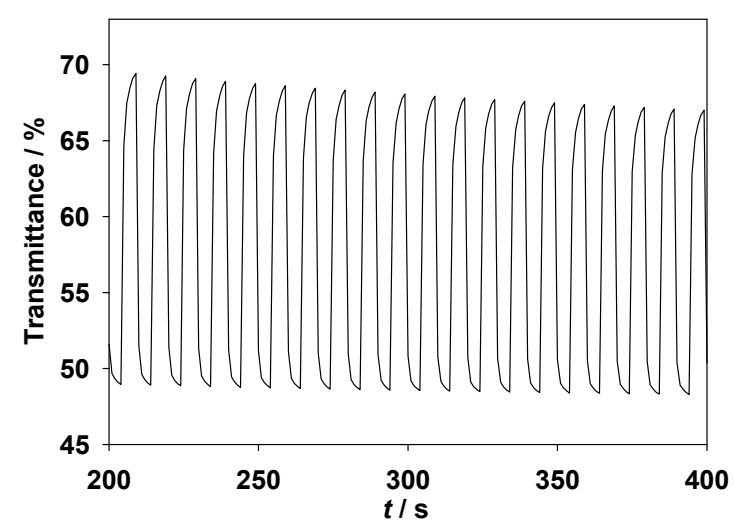

(c)

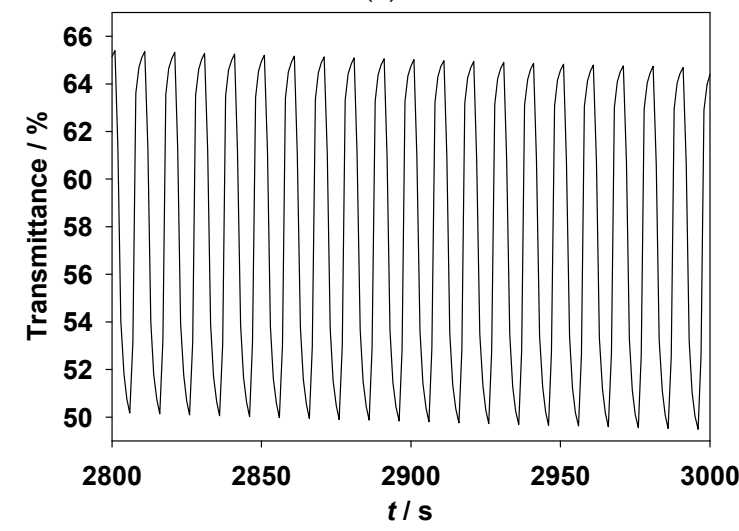

(e)

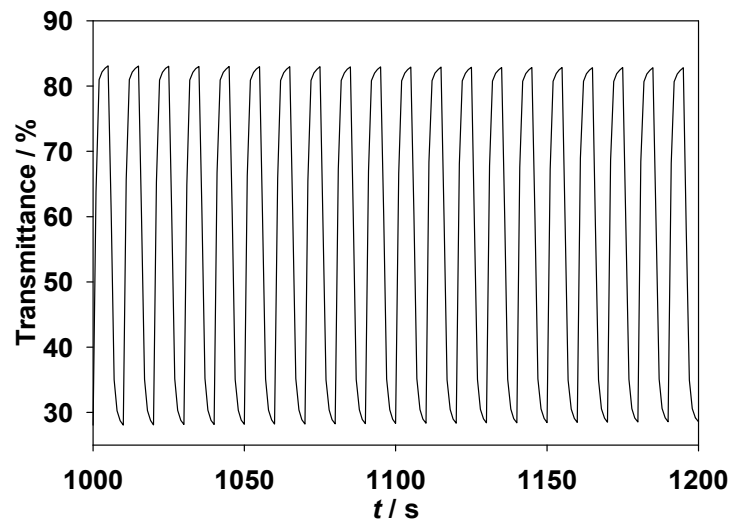

(b)

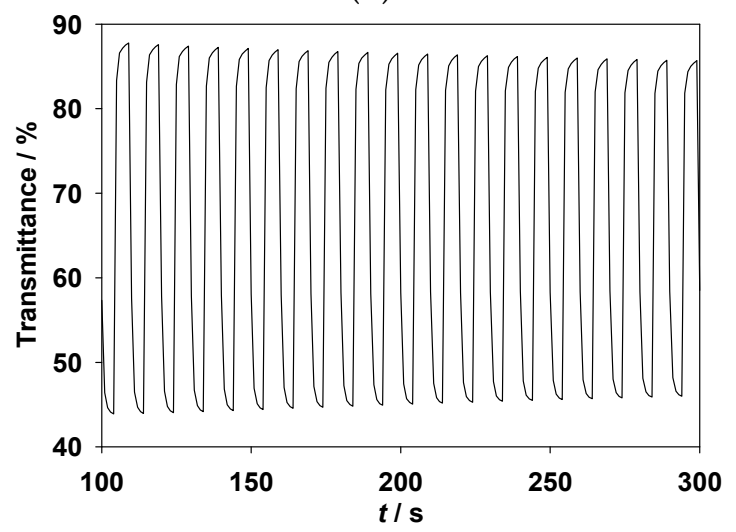

(d)

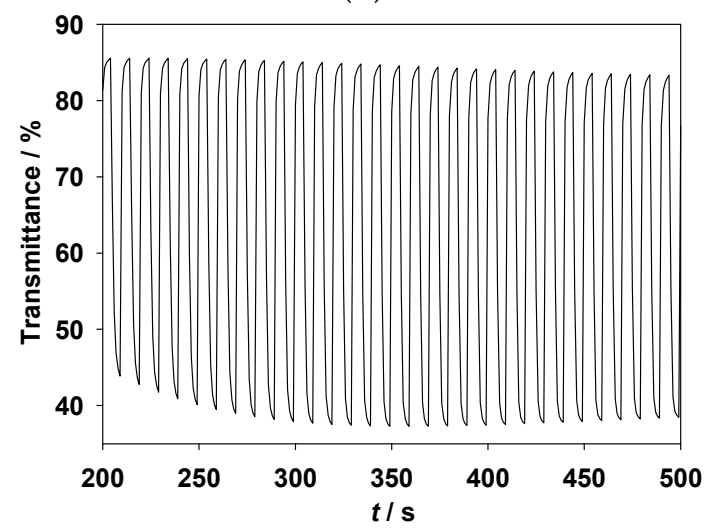

(f)

Figure 6. In situ transmittance of (a) PMPS film at $600 \mathrm{~nm}$; (b) PMPS film at $940 \mathrm{~nm}$; (c) PMPO film at $584 \mathrm{~nm}$; (d) PMPO film at $950 \mathrm{~nm}$; (e) PANIL film at $566 \mathrm{~nm}$; and (f) PANIL film at $950 \mathrm{~nm}$ as a function of time in $\left[\mathrm{EPI}^{+}\right]\left[\mathrm{TFSI}^{-}\right]$solution. The time interval is $5 \mathrm{~s}$. The conducting polymer films were stepped by repeated potential between -0.2 and $+0.9 \mathrm{~V}$. 


\subsection{Spectroelectrochemistry of ECDs}

Dual-type ECDs composed of two electrochromic electrodes, one anodically coloring layer (PMPS, PMPO, or PANIL) and the other cathodically coloring material (PProDOT-Et ${ }_{2}$ ), were facing each other and were separated by an electrolyte membrane. Figure 7a shows the spectroelectrochemical spectra of the PMPS/PProDOT-Et $t_{2}$ ECD at potentials between $-0.4 \mathrm{~V}$ and $+1.6 \mathrm{~V}$. PMPS/PProDOT-Et PCD $_{2}$ shows a peak at around $380 \mathrm{~nm}$ and a shoulder at around $430 \mathrm{~nm}$ at $0 \mathrm{~V}$, and this can be attributed to the $\pi-\pi^{*}$ transition peak of the PMPS film in the neutral state. In this situation, PProDOT-Et W $_{2}$ light blue in its oxidation state, and the PMPS/PProDOT-Et ${ }_{2}$ ECD was greyish-green at $0 \mathrm{~V}$. However, the absorption of the $\pi-\pi^{*}$ transition peak for the PMPS film lessened and a new peak at $590 \mathrm{~nm}$ emerged at $+1.6 \mathrm{~V}$, and the PMPS/PProDOT-Et ${ }_{2}$ ECD was cyan at $+1.6 \mathrm{~V}$. Under similar conditions, the PMPO/PProDOT-Et ${ }_{2}$ ECD was light green at $-0.4 \mathrm{~V}$, bluish-grey at $0.6 \mathrm{~V}$, light blue at $0.8 \mathrm{~V}$, and blue at $1.6 \mathrm{~V}$. The PANIL/PProDOT-Et ${ }_{2}$ ECD was grey at $-0.4 \mathrm{~V}$, light blue at $0.8 \mathrm{~V}$, and blue at $1.6 \mathrm{~V}$. The CIE chromaticity values $(x, y)$ and colorimetric values $\left(L, a, b, L^{*}, a^{*}, b^{*}\right)$ of the PMPS/PProDOT-Et ${ }_{2}$, $\mathrm{PMPO} / \mathrm{PProDOT}-\mathrm{Et}_{2}$, and PANIL/PProDOT-Et ${ }_{2}$ dual type ECDs are summarized in Table 4. Moreover, the CIE chromaticity diagrams of the PMPS/PProDOT-Et ${ }_{2}$ ECD at -0.6 and 1.6 V, PMPO/PProDOT-Et 2 ECD at -0.4 and $1.8 \mathrm{~V}$, and PANIL/PProDOT-Et ${ }_{2}$ ECD at -0.4 and $1.8 \mathrm{~V}$ are displayed in Figure 8.

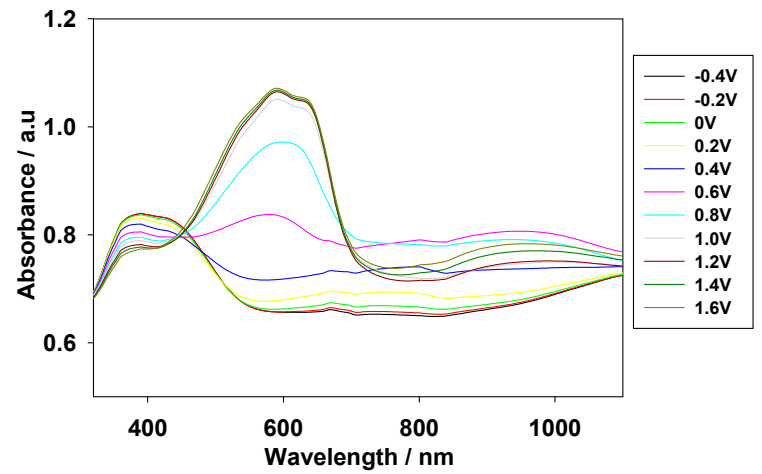

(a)

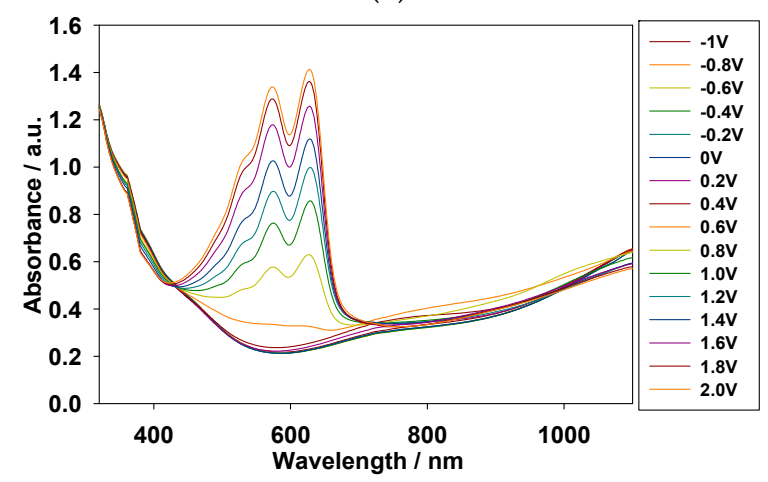

(c)

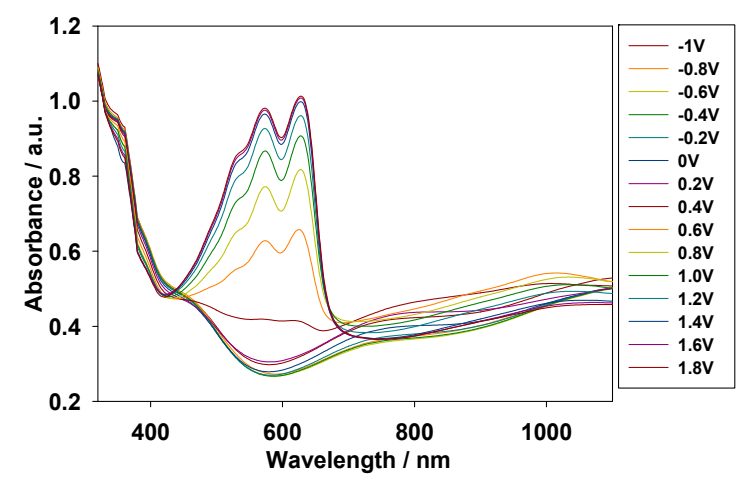

(b)

Figure 7. Spectroelectrochemical spectra of (a) PMPS/PProDOT-Et 2 ; (b) PMPO/PProDOT-Et Pr $_{2}$ and (c) PANIL/PProDOT-Et $t_{2}$ ECDs at various potentials. 


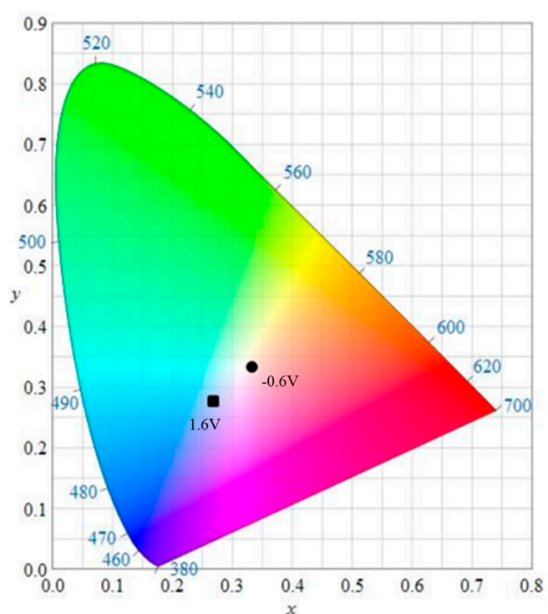

(a)

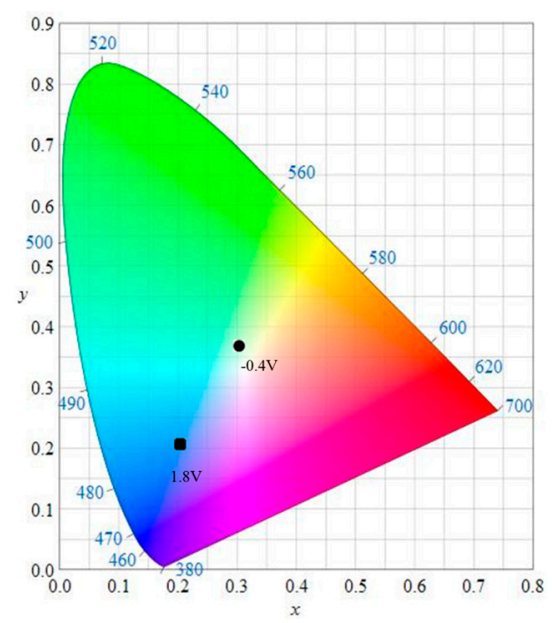

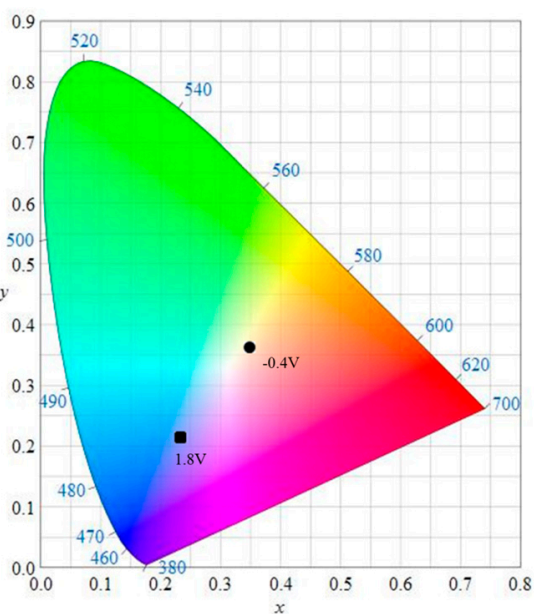

(b)

(c)

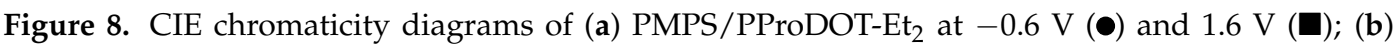
PMPO/PProDOT-Et 2 at $-0.4 \mathrm{~V}(\bullet)$ and $1.8 \mathrm{~V}(\boldsymbol{\bullet})$; and (c) PANIL/PProDOT-Et at $_{2}-0.4 \mathrm{~V}(\bullet)$ and $1.8 \mathrm{~V}(\mathbf{\square})$.

Table 4. The colorimetric values $\left(L, a, b, L^{*}, a^{*}, b^{*}\right)$ and CIE chromaticity values $(x, y)$ of PMPS/ PProDOT-Et $t_{2}$ PMPO/PProDOT-Et ${ }_{2}$, and PANIL/PProDOT-Et ${ }_{2}$ ECDs at different applied potentials.

\begin{tabular}{cccccccccc}
\hline ECDs & $\boldsymbol{E} / \mathbf{V}$ & $\boldsymbol{L}$ & $\boldsymbol{a}$ & $\boldsymbol{b}$ & $\boldsymbol{L}^{*}$ & $\boldsymbol{a}^{*}$ & $\boldsymbol{b}^{*}$ & $\boldsymbol{x}$ & $\boldsymbol{y}$ \\
\hline & -0.6 & 78.12 & -1.07 & 11.74 & 82.39 & -0.02 & 12.28 & 0.3354 & 0.3449 \\
& -0.4 & 78.13 & -1.13 & 11.79 & 82.4 & -0.08 & 12.33 & 0.3355 & 0.345 \\
& -0.2 & 78.13 & -1.27 & 11.77 & 82.4 & -0.23 & 12.31 & 0.3352 & 0.3451 \\
& 0 & 78 & -1.67 & 11.35 & 82.3 & -0.65 & 11.8 & 0.3335 & 0.3444 \\
PMPS/PProDOT-Et $_{2}$ & 0.2 & 77.44 & -2.18 & 10.21 & 81.82 & -1.19 & 10.48 & 0.33 & 0.3421 \\
& 0.4 & 75.55 & -1.87 & 7.83 & 80.22 & -0.9 & 7.77 & 0.3252 & 0.3364 \\
& 0.6 & 69.94 & 0.1 & 1.09 & 75.4 & 1.13 & 0.32 & 0.3129 & 0.3189 \\
& 0.8 & 64.41 & -0.34 & -6.29 & 70.52 & 0.58 & -7.49 & 0.2942 & 0.3009 \\
& 1.0 & 61.4 & 0.1 & -10.71 & 67.8 & 1.05 & -11.97 & 0.2839 & 0.2893 \\
& 1.2 & 60.73 & 0.72 & -12.22 & 67.18 & 1.73 & -13.46 & 0.2814 & 0.2851 \\
& 1.4 & 60.42 & 1.34 & -13.27 & 66.91 & 2.43 & -14.47 & 0.2801 & 0.2822 \\
& 1.6 & 60.06 & 1.91 & -13.56 & 66.57 & 3.07 & -14.76 & 0.2804 & 0.2809 \\
\hline
\end{tabular}


Table 4. Cont.

\begin{tabular}{cccccccccc}
\hline ECDs & $\boldsymbol{E} \mathbf{V}$ & $\boldsymbol{L}$ & $\boldsymbol{a}$ & $\boldsymbol{b}$ & $\boldsymbol{L}^{*}$ & $\boldsymbol{a}^{*}$ & $\boldsymbol{b}^{*}$ & $\boldsymbol{x}$ & $\boldsymbol{y}$ \\
\hline & -0.4 & 69.99 & -1.97 & 16.09 & 75.44 & -1.11 & 18.83 & 0.3498 & 0.3626 \\
& -0.2 & 69.92 & -2.32 & 15.75 & 75.38 & -1.49 & 18.37 & 0.3482 & 0.362 \\
& 0 & 69.45 & -2.75 & 14.84 & 74.97 & -1.97 & 17.17 & 0.3449 & 0.3599 \\
& 0.2 & 67.75 & -2.44 & 12.62 & 73.48 & -1.68 & 14.35 & 0.3397 & 0.3538 \\
& 0.4 & 61.31 & -1.16 & 5.04 & 67.72 & -0.38 & 5.12 & 0.322 & 0.332 \\
PMPO/PProDOT-Et 2 & 0.6 & 51.91 & -1.54 & -7.26 & 58.93 & -1 & -8.84 & 0.2851 & 0.2958 \\
& 0.8 & 46.45 & -0.32 & -14.88 & 53.58 & 0.38 & -16.8 & 0.2641 & 0.2704 \\
& 1.0 & 42.8 & 1.68 & -19.68 & 49.88 & 2.84 & -21.55 & 0.2532 & 0.2526 \\
& 1.2 & 40.43 & 3.4 & -22.6 & 47.43 & 5.03 & -24.36 & 0.2476 & 0.2409 \\
& 1.4 & 38.94 & 4.52 & -24.8 & 45.86 & 6.47 & -26.39 & 0.2431 & 0.2326 \\
& 1.6 & 38.48 & 4.79 & -25.17 & 45.37 & 6.82 & -26.75 & 0.2423 & 0.2307 \\
& 1.8 & 38.23 & 5.13 & -25.7 & 45.1 & 7.26 & -27.22 & 0.2415 & 0.2288 \\
\hline & -0.4 & 74.98 & -4.17 & 19.46 & 79.74 & -3.36 & 22.84 & 0.3526 & 0.3715 \\
& -0.2 & 75 & -4.33 & 19.37 & 79.75 & -3.53 & 22.71 & 0.352 & 0.3713 \\
& 0 & 74.85 & -4.6 & 19.02 & 79.63 & -3.83 & 22.24 & 0.3506 & 0.3706 \\
& 0.2 & 74.5 & -4.9 & 18.3 & 79.33 & -4.16 & 21.27 & 0.3482 & 0.369 \\
& 0.4 & 73.33 & -4.61 & 17.25 & 78.33 & -3.89 & 19.97 & 0.3463 & 0.3664 \\
PANIL/PProDOT-Et 2 & 0.6 & 66.93 & -2.76 & 11.09 & 72.76 & -2.05 & 12.41 & 0.3349 & 0.3498 \\
& 0.8 & 55.45 & -4.98 & -2.59 & 62.29 & -5.02 & -3.69 & 0.2916 & 0.3135 \\
& 1.0 & 48.59 & -4.69 & -11.81 & 55.7 & -5.01 & -13.66 & 0.2634 & 0.2843 \\
& 1.2 & 44.1 & -2.96 & -18.32 & 51.2 & -3.01 & -20.21 & 0.2465 & 0.2615 \\
& 1.4 & 40.04 & -0.32 & -24.33 & 47.01 & 0.28 & -25.89 & 0.2334 & 0.2392 \\
& 1.6 & 35.72 & 3.14 & -30.97 & 42.4 & 4.81 & -31.75 & 0.2204 & 0.214 \\
& 1.8 & 32.91 & 5.48 & -35.32 & 39.29 & 7.97 & -35.34 & 0.212 & 0.1975 \\
\hline
\end{tabular}

The transmittance-time profiles of the PMPS/PProDOT-Et ${ }_{2}$, PMPO/PProDOT-Et $_{2}$, and PANIL/PProDOT-Et ${ }_{2}$ ECDs are shown in Figure 9. The $\Delta T_{\max } \%$ of the PMPS/PProDOT-Et ${ }_{2}$, $\mathrm{PMPO} / \mathrm{PProDOT}_{-\mathrm{Et}_{2} \text {, and PANIL/PProDOT-Et }}$ ECDs were $33 \%$ at $590 \mathrm{~nm}, 41 \%$ at $626 \mathrm{~nm}$, and $25 \%$ at $628 \mathrm{~nm}$, respectively. The $\eta$ of the PMPS/PProDOT-Et $t_{2}$, PMPO/PProDOT-Et ${ }_{2}$, and PANIL/PProDOT-Et ${ }_{2}$ ECDs, calculated from Equations (1) and (2), were found to be 637.25 $\mathrm{cm}^{2} \cdot \mathrm{C}^{-1}$ at $590 \mathrm{~nm}, 674.67 \mathrm{~cm}^{2} \cdot \mathrm{C}^{-1}$ at $626 \mathrm{~nm}$, and $401.63 \mathrm{~cm}^{2} \cdot \mathrm{C}^{-1}$ at $628 \mathrm{~nm}$, respectively. The PMPS/PProDOT-Et ${ }_{2}$ and PMPO/PProDOT-Et $t_{2}$ ECDs showed higher $\Delta T_{\max } \%$ and $\eta$ than those of the PANIL/PProDOT-Et ${ }_{2}$ ECDs, indicating that the incorporations of the methoxyphenyl- and methylthiophenyl-substituted PSNS into the ECDs gave rise to higher $\Delta T_{\max } \%$ and $\eta$ than those of the benzonitrile-substituted PSNS. The $\Delta T_{\max }, \Delta \mathrm{OD}$, and $\eta_{\max }$ of the PMPS/PProDOT-Et ${ }_{2}$, PMPO/PProDOT-Et $t_{2}$, and PANIL/PProDOT-Et ${ }_{2}$ ECDs are summarized in Table 5. The $\tau_{\mathrm{c}}$ and $\tau_{\mathrm{b}}$ estimated at various double-step potential cycles are listed in Table 3, and the $T_{95 \%}$ of the PMPS/PProDOT-Et $t_{2}$ ECD at $590 \mathrm{~nm}$ was estimated to be $0.99 \mathrm{~s}$ from the bleaching state to the coloring state and $1.01 \mathrm{~s}$ from the coloring state to the bleaching state at the 100th cycle. Under similar conditions, the $T_{95 \%}$ of the PMPO/PProDOT-Et $t_{2}$ ECD at $626 \mathrm{~nm}$ was estimated to be $1.42 \mathrm{~s}$ from the bleaching state to the coloring state and $1.12 \mathrm{~s}$ from the coloring state to the bleaching state at the 100th cycle, and the $T_{95 \%}$ of the PANIL/PProDOT-Et $t_{2}$ ECD at $628 \mathrm{~nm}$ was estimated to be $1.17 \mathrm{~s}$ from the bleaching state to the coloring state and $1.06 \mathrm{~s}$ from the coloring state to the bleaching state. The PMPS/PProDOT-Et ${ }_{2}$ ECD shows shorter $\tau_{\mathrm{c}}$ than those of the PMPO/PProDOT-Et $t_{2}$ and PANIL/PProDOT-Et ${ }_{2}$ ECDs at the 100th cycle, implying that the PMPS/PProDOT-Et ${ }_{2}$ ECD changes color faster from the bleaching state to the coloring state than those of the PMPO/PProDOT-Et $\mathrm{P}_{2}$ and PANIL/PProDOT-Et ${ }_{2}$ ECDs. 
Table 5. Comparisons of the $\Delta T_{\max }$ and $\eta_{\max }$ for various polymer films and ECDs.

\begin{tabular}{|c|c|c|c|c|c|}
\hline Polymer Films and ECDs & $\lambda / \mathbf{n m}$ & $E_{\mathrm{g}} / \mathrm{eV}$ & $\Delta T_{\max } / \%$ & $\Delta \mathrm{OD}_{\max } / \%$ & $\eta_{\max } / \mathrm{cm}^{2} \cdot \mathrm{C}^{-1}$ \\
\hline PMPS & 940 & 2.17 & 54.74 & 46.40 & 298.28 \\
\hline PMPO & 890 & 2.25 & 43.87 & 30.04 & 142.48 \\
\hline PANIL & 950 & 2.21 & 44.63 & 34.94 & 279.19 \\
\hline PMPS/PProDOT-Et ${ }_{2}$ ECD & 590 & - & 32.51 & 54.45 & 637.25 \\
\hline PMPO/PProDOT-Et ${ }_{2}$ ECD & 626 & - & 41.13 & 52.40 & 674.67 \\
\hline $\begin{array}{c}\text { PANIL/PProDOT-Et }{ }_{2} \\
\text { ECD }\end{array}$ & 628 & - & 25.00 & 29.80 & 401.63 \\
\hline
\end{tabular}

The long-term switching stability of the ECDs between the bleaching and coloring states is an important parameter in practical applications of ECDs [38,39]. The cycling stability of the PMPS/PProDOT-Et ${ }_{2}, \mathrm{PMPO} / \mathrm{PProDOT}_{-} \mathrm{Et}_{2}$, and PANIL/PProDOT-Et $\mathrm{E}_{2} \mathrm{ECDs}_{\text {sere measured }}$ using $\mathrm{CV}$ at potentials between -0.4 and $+1.4 \mathrm{~V}$ with a scan rate of $100 \mathrm{mV} \cdot \mathrm{s}^{-1}$. As shown in Figure 10,94\%, 91\%, and 90\% of the electrical activity was retained after 500 cycles for the PMPS/PProDOT-Et ${ }_{2}$, PMPO/PProDOT-Et ${ }_{2}$, and PANIL/PProDOT-Et ${ }_{2}$ ECDs, respectively, and $91 \%, 89 \%$, and $87 \%$ of the electrical activity was retained after 1000 cycles for the PMPS/PProDOT-Et $t_{2}$, PMPO/PProDOT-Et $t_{2}$, and PANIL/PProDOT-Et $t_{2}$ ECDs, respectively, indicating that the PMPS/PProDOT-Et ${ }_{2}$, PMPO/PProDOT-Et ${ }_{2}$, and PANIL/PProDOT-Et ${ }_{2}$ ECDs displayed reasonable long-term cycling stability.

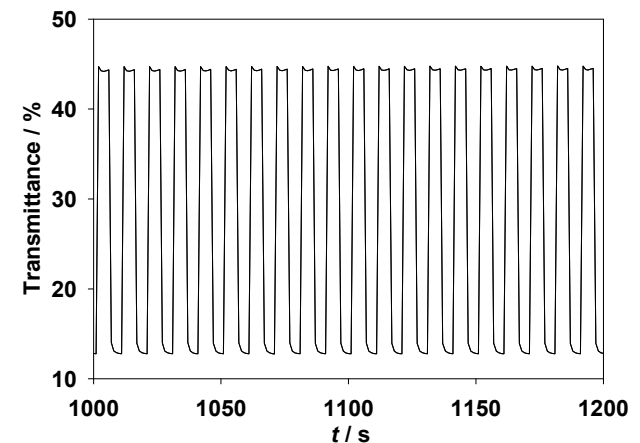

(a)

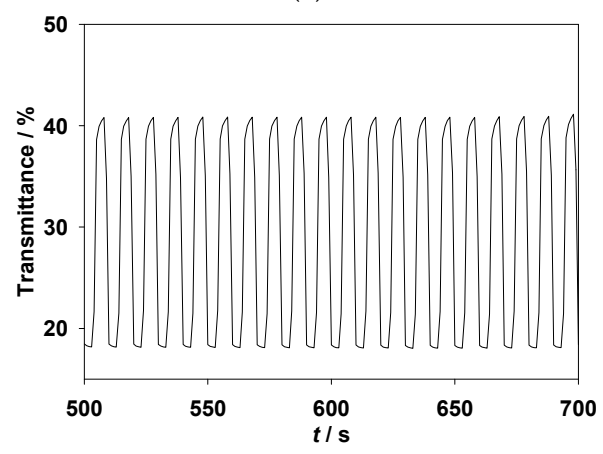

(c)

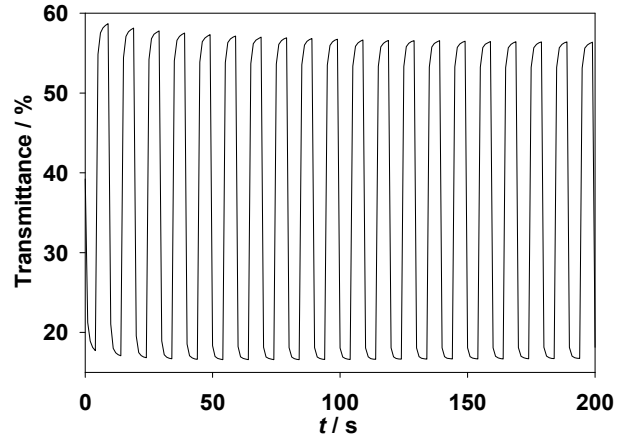

(b)

Figure 9. In situ transmittance of (a) PMPS/PProDOT-Et ${ }_{2}$ ECD at $590 \mathrm{~nm}$ as a function of time, the ECD was stepped by repeated potential between -0.4 and $+1.0 \mathrm{~V}$; (b) PMPO/PProDOT-Et ${ }_{2}$ ECD at $626 \mathrm{~nm}$, the ECD was stepped by repeated potential between -0.4 and $1.2 \mathrm{~V}$; and (c) PANIL/PProDOT-Et ${ }_{2}$ ECDs at $628 \mathrm{~nm}$, the ECD was stepped by repeated potential between 0 and $1.2 \mathrm{~V}$. 


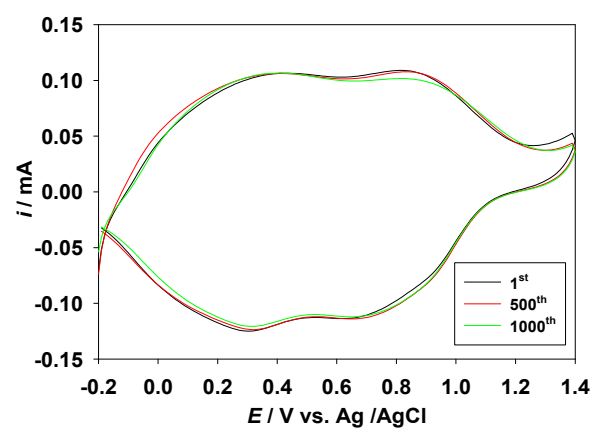

(a)

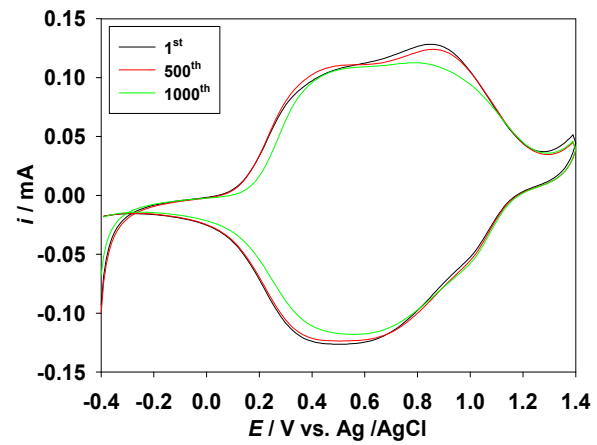

(c)

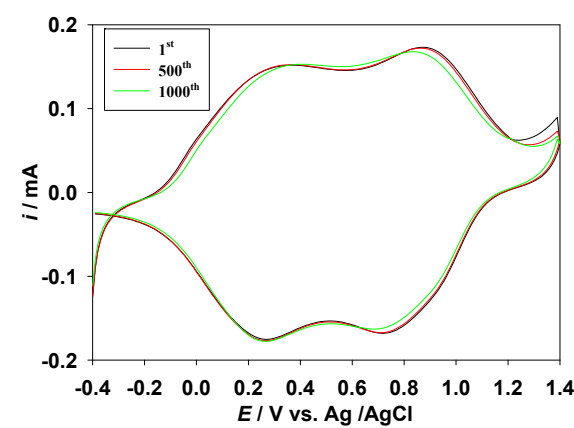

(b)

Figure 10. Cyclic voltammograms of (a) PMPS/PProDOT-Et 2 ; (b) PMPO/PProDOT-Et 2 , and (c) PANIL/PProDOT-Et $t_{2}$ ECDs as a function of repeated scans at $100 \mathrm{mV} \cdot \mathrm{s}^{-1}$.

The optical memory effect is also important for ECD applications [40]. The optical memory of the PMPS/PProDOT-Et 2 , PMPO/PProDOT-Et , $_{2}$ and PANIL/PProDOT-Et 2 ECDs was evaluated at 590,626 , and $628 \mathrm{~nm}$, respectively, with the function of time at $-0.4 \mathrm{~V}$ and $+1.0 \mathrm{~V}$ by applying a potential for $1 \mathrm{~s}$ for each $200 \mathrm{~s}$ time interval. As shown in Figure 11a-c, the PMPS/PProDOT-Et ${ }_{2}$, PMPO/PProDOT-Et $t_{2}$, and PANIL/PProDOT-Et ${ }_{2}$ ECDs showed good optical memories in a reduced state of the PMPS, PMPO, and PANIL films, and the transmittance change of the PMPS, PMPO, and PANIL films is less than $1 \%$ in their reduced states. However, in the oxidized state of the PMPS, PMPO, and PANIL films and in the reduced state of the PProDOT-Et $t_{2}$ film, the PMPS/PProDOT-Et ${ }_{2}$, PMPO/PProDOT-Et $t_{2}$, and PANIL/PProDOT-Et $t_{2}$ ECDs are less stable than the oxidized state of the PProDOT-Et $t_{2}$ film, but the transmittance change is less than $3 \%$ in the oxidized state of the PMPS, PMPO, and PANIL films, demonstrating that the PMPS/PProDOT-Et ${ }_{2}$, PMPO/PProDOT-Et ${ }_{2}$, and PANIL/PProDOT-Et 2 ECDs show reasonable optical memory in the coloring and bleaching states.

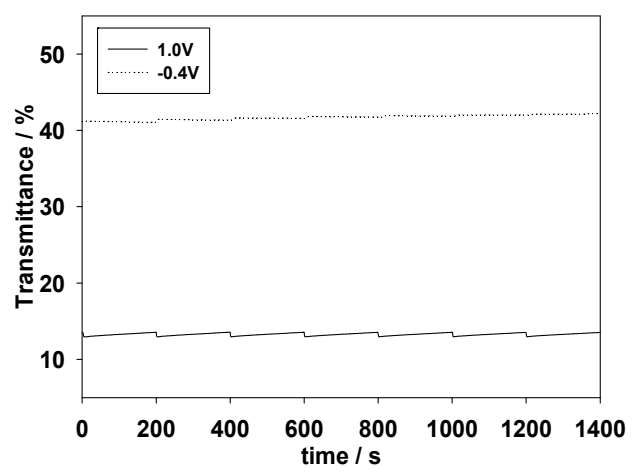

(a)

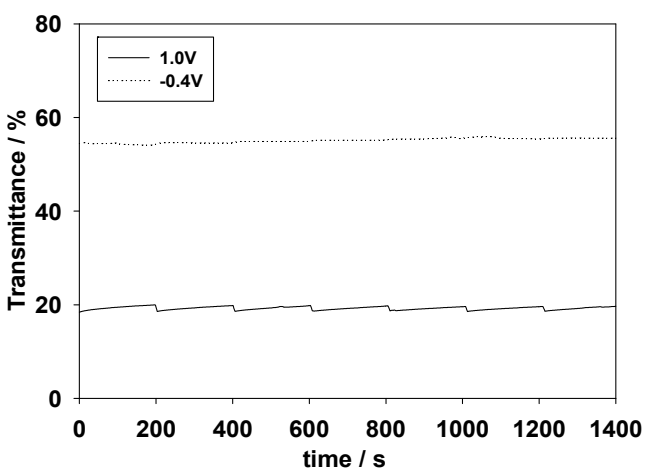

(b)

Figure 11. Cont. 


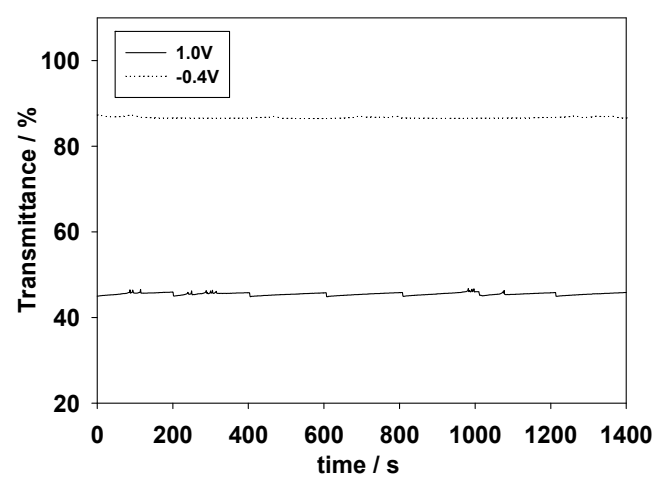

(c)

Figure 11. Open circuit stability of (a) PMPS/PProDOT-Et $t_{2}$ ECD monitored at $590 \mathrm{~nm}$; (b) PMPO/PProDOT-Et $t_{2}$ ECD monitored at $626 \mathrm{~nm}$; and (c) PANIL/PProDOT-Et ${ }_{2}$ ECD monitored at $628 \mathrm{~nm}$.

\section{Conclusions}

The dithienylpyrrole derivative (MPS) was synthesized via a Knorr-Paal reaction and its corresponding homopolymer (PMPS) was prepared using electrochemical polymerization. According to the spectroelectrochemical analysis, the PMPS, PMPO, and PANIL films revealed distinct electrochromic properties $\left(\Delta T_{\max } \geq 43.87 \%\right.$ ) at various potentials in an ionic liquid solution. The PMPS film showed a higher coloration efficiency $\left(\eta_{\max }=298.28 \mathrm{~cm}^{2} \cdot \mathrm{C}^{-1}\right)$ than those of the PMPO and PANIL films. Dual-type complementary ECDs consisting of PMPS, PMPO, and PANIL films as anodically coloring materials and PProDOT-Et ${ }_{2}$ as the cathodically coloring material were fabricated. Spectroelectrochemical studies showed that the PMPS/PProDOT-Et ${ }_{2}$ ECD is greyish-green and cyan at 0 and $+1.6 \mathrm{~V}$, respectively. Electrochromic switching studies showed that the PMPS/PProDOT-Et 2 ECD exhibited high $\Delta T_{\max }(32.51 \%)$ and coloration efficiency $\left(637.25 \mathrm{~cm}^{2} \cdot \mathrm{C}^{-1}\right)$ at $590 \mathrm{~nm}$. Considering these results, PMPS film is a promising anodic layer for electrochromic applications.

Author Contributions: Tzi-Yi Wu and Yuh-Shan Su designed and conceived the experiments, Yuh-Shan $\mathrm{Su}$ implemented the experiments, Yuh-Shan Su, Jui-Cheng Chang, and Tzi-Yi Wu characterized the electrochromic properties.

Conflicts of Interest: The authors declare no conflict of interest.

\section{References}

1. Hacioglu, S.O.; Yiğit, D.; Ermis, E.; Soylemez, S.; Güllü, M.; Toppare, L. Syntheses and electrochemical characterization of low oxidation potential nitrogen analogs of pedot as electrochromic materials. J. Electrochem. Soc. 2016, 163, E293-E299. [CrossRef]

2. Du, Q.; Wei, Y.; Zheng, J.; Xu, C. Donor- $\pi$-bridge-acceptor type polymeric materials with pendant electron-withdrawing groups for electrochromic applications. Electrochim. Acta 2014, 132, 258-264. [CrossRef]

3. Carbas, B.B.; Kivrak, A.; Teke, E.; Zora, M.; Önal, A.M. Electrochemical polymerization of a new low-voltage oxidized thienylenepyrrole derivative and its electrochromic device application. J. Electroanal. Chem. 2014, 729, 15-20. [CrossRef]

4. Yu, G.; Gao, J.; Hummelen, J.C.; Wudl, F.; Heeger, A.J. Polymer photovoltaic cells: Enhanced efficiencies via a network of internal donor-acceptor heterojunctions. Science 1995, 270, 1789-1791. [CrossRef]

5. Wu, T.Y.; Sheu, R.B.; Chen, Y. Synthesis, optically acid-sensory and electrochemical properties of novel polyoxadiazole derivatives. Macromolecules 2004, 37, 725-733. [CrossRef]

6. Wu, T.Y.; Chen, Y. Poly(phenylene vinylene)-based copolymers containing 3,7-phenothiazylene and 2,6-pyridylene chromophores: Fluorescence sensors for acids, metal ions, and oxidation. J. Polym. Sci. Part A Polym. Chem. 2004, 42, 1272-1284. 
7. Yen, H.J.; Chang, J.H.; Wu, J.H.; Liou, G.S. The steric effect of $\alpha$ - and $\beta$-substituted anthraquinone units on high performance polymeric memory devices. Polym. Chem. 2015, 6, 7758-7763. [CrossRef]

8. Huang, T.T.; Tsai, C.L.; Hsiao, S.H.; Liou, G.S. Linkage and donor-acceptor effects on resistive switching memory devices of 4-(N-carbazolyl)triphenylamine-based polymers. RSC Adv. 2016, 6, 28815-28819. [CrossRef]

9. Wu, T.Y.; Kuo, C.W.; Chen, Y.L.; Chang, J.K. Copolymers based on indole-6-carboxylic acid and 3,4-ethylenedioxythiophene as platinum catalyst support for methanol oxidation. Catalysts 2015, 5, 1657-1672. [CrossRef]

10. Kuo, C.W.; Kuo, Z.Y.; Jow, J.J.; Wu, T.Y.; Chen, J.Y.; Zhu, X.X. Enhanced electrocatalytic performance for methanol oxidation via insertion of ruthenium oxide particles into $\mathrm{Pt}$ and polyaniline-poly(acrylic acid-co-maleic acid) composite electrode. Int. J. Electrochem. Sci. 2012, 7, 4974-4987. [CrossRef]

11. Kuo, C.W.; Chen, S.J.; Chen, P.R.; Tsai, W.T.; Wu, T.Y. Doping process effect of polyaniline doped with poly(styrenesulfonic acid) supported platinum for methanol oxidation. J. Taiwan Inst. Chem. Eng. 2013, 44, 497-504. [CrossRef]

12. Wu, T.Y.; Chen, Y. Synthesis, optical and electrochemical properties of novel copolymers containing alternate 2,3-quinoxaline and hole-transporting units. J. Polym. Sci. Part. A Polym. Chem. 2002, 40, 4570-4580. [CrossRef]

13. Wu, T.Y.; Chen, Y. Synthesis and characterization of novel luminescent polymers with alternate phenothiazine and divinylbenzene units. J. Polym. Sci. Part A Polym. Chem. 2002, 40, 4452-4462. [CrossRef]

14. Seshadri, V.; Padilla, J.; Bircan, H.; Radmard, B.; Draper, R.; Wood, M.; Otero, T.F.; Sotzing, G.A. Optimization, preparation, and electrical short evaluation for $30 \mathrm{~cm}^{2}$ active area dual conjugated polymer electrochromic windows. Org. Electron. 2007, 8, 367-381. [CrossRef]

15. Mortimer, R.J. Organic electrochromic materials. Electrochim. Acta 1999, 44, 2971-2981. [CrossRef]

16. Krukiewicz, K.; Jarosz, T.; Herman, A.P.; Turczyn, R.; Boncel, S.; Zak, J.K. The effect of solvent on the synthesis and physicochemical properties of poly(3,4-ethylenedioxypyrrole). Synth. Met. 2016, 217, 231-236. [CrossRef]

17. Lin, K.; Zhang, S.; Liu, H.; Zhao, Y.; Wang, Z.; Xu, J. Effects on the electrochemical and electrochromic properties of 3 linked polythiophene derivative by the introduction of polyacrylate. Int. J. Electrochem. Sci. 2015, 10, 7720-7731.

18. Ming, S.; Zhang, S.; Liu, H.; Zhao, Y.; Mo, D.; Xu, J. Methacrylate modified polythiophene: Electrochemistry and electrochromics. Int. J. Electrochem. Sci. 2015, 10, 6598-6609.

19. Kuo, C.W.; Chen, B.K.; Li, W.B.; Tseng, L.Y.; Wu, T.Y.; Tseng, C.G.; Chen, H.R.; Huang, Y.C. Effects of supporting electrolytes on spectroelectrochemical and electrochromic properties of polyaniline-poly(styrene sulfonic acid) and poly(ethylenedioxythiophene)-poly(styrene sulfonic acid)-based electrochromic device. J. Chin. Chem. Soc. 2014, 61, 563-570. [CrossRef]

20. Hsiao, S.H.; Hsueh, J.C. Electrochemical synthesis and electrochromic properties of new conjugated polycarbazoles from di(carbazol-9-yl)-substituted triphenylamine and $N$-phenylcarbazole derivatives. J. Electroanal. Chem. 2015, 758, 100-110. [CrossRef]

21. Hsiao, S.H.; Lin, S.W. The electrochemical fabrication of electroactive polymer films from diamide- or diimide-cored $\mathrm{N}$-phenylcarbazole dendrons for electrochromic applications. J. Mater. Chem. C 2016, 4, 1271-1280. [CrossRef]

22. Rende, E.; Kilic, C.E.; Udum, Y.A.; Toffoli, D.; Toppare, L. Electrochromic properties of multicolored novel polymer synthesized via combination of benzotriazole and $N$-functionalized 2,5-di(2-thienyl)-1H-pyrrole units. Electrochim. Acta 2014, 138, 454-463. [CrossRef]

23. Cansu-Ergun, E.G.; Onal, A.M.; Cihaner, A. Propylenedioxy and benzimidazole based electrochromic polymers. J. Electrochem. Soc. 2016, 163, G53-G60. [CrossRef]

24. Wu, T.Y.; Su, S.G.; Gung, S.T.; Lin, M.W.; Lin, Y.C.; Lai, C.A.; Sun, I.W. Ionic liquids containing an alkyl sulfate group as potential electrolytes. Electrochim. Acta 2010, 55, 4475-4482. [CrossRef]

25. Kuo, C.W.; Hao, L.; Kuo, P.L.; Chen, P.R.; Wu, T.Y. Influence of lithium salt addition on ionic conductivity and transporting properties of lithium bis(trifluoromethanesulfonyl)imide-doped glycine-based ionic liquid electrolyte. J. Taiwan Inst. Chem. Eng. 2014, 45, 1270-1279. [CrossRef]

26. Wu, T.Y.; Wang, H.C.; Su, S.G.; Gung, S.T.; Lin, M.W.; Lin, C.B. Characterization of ionic conductivity, viscosity, density, and self-diffusion coefficient for binary mixtures of polyethyleneglycol (or polyethyleneimine) 
organic solvent with room temperature ionic liquid $\mathrm{BMIBF}_{4}$ (or $\mathrm{BMIPF}_{6}$ ). J. Taiwan Inst. Chem. Eng. 2010, 41, 315-325. [CrossRef]

27. Sun, I.W.; Wang, H.P.; Teng, H.; Su, S.G.; Lin, Y.C.; Kuo, C.W.; Chen, P.R.; Wu, T.Y. Cyclic ammonium-based ionic liquids as potential electrolytes for dye-sensitized solar cells. Int. J. Electrochem. Sci. 2012, 7, 9748-9764.

28. Chen, B.-K.; Wu, T.-Y.; Wong, J.-M.; Chang, Y.-M.; Lee, H.-F.; Huang, W.-Y.; Chen, A.F. Highly Sulfonated Diamine Synthesized Polyimides and Protic Ionic Liquid Composite Membranes Improve PEM Conductivity. Polymers 2015, 7, 1046-1065. [CrossRef]

29. Welsh, D.M.; Kumar, A.; Meijer, E.W.; Reynolds, J.R. Enhanced contrast ratio and rapid switching in electrochromics based on poly(3,4-propylenedioxythiophene) derivatives. Adv. Mater. 1999, 11, 1379-1382. [CrossRef]

30. Wu, T.Y.; Chen, B.K.; Hao, L.; Lin, K.F.; Sun, I.W. Thermophysical properties of a room temperature ionic liquid (1-methyl-3-pentyl-imidazolium hexafluorophosphate) with poly(ethylene glycol). J. Taiwan Inst. Chem. Eng. 2011, 42, 914-921. [CrossRef]

31. Tarkuc, S.; Sahmetlioglu, E.; Tanyeli, C.; Akhmedov, I.M.; Toppare, L. Electrochromic properties of a soluble conducting polymer of 1-benzyl-2,5-di(thiophene-2-yl)-1H-pyrrole. Sens. Actuators B 2007, 121, 622-628. [CrossRef]

32. Wu, T.Y.; Liao, J.W.; Chen, C.Y. Electrochemical synthesis, characterization and electrochromic properties of indan and 1,3-benzodioxole-based poly(2,5-dithienylpyrrole) derivatives. Electrochim. Acta 2014, 150, 245-262. [CrossRef]

33. Wu, T.Y.; Chung, H.H. Applications of tris(4-(thiophen-2-yl)phenyl)amine- and dithienylpyrrole-based conjugated copolymers in high-contrast electrochromic devices. Polymers 2016, 8, 206. [CrossRef]

34. Tsao, M.H.; Wu, T.Y.; Wang, H.P.; Sun, I.W.; Su, S.G.; Lin, Y.C.; Chang, C.W. An efficient metal free sensitizer for dye-sensitized solar cells. Mater. Lett. 2011, 65, 583-586. [CrossRef]

35. Wu, T.Y.; Chen, Y. Synthesis and characterization of luminescent copolymers containing iminodibenzyl and divinylbenzene chromophores. J. Polym. Sci. Part A Polym. Chem. 2002, 40, 3847-3857. [CrossRef]

36. Soyleyici, S.; Karakus, M.; Ak, M. Transparent-blue colored dual type electrochromic device: Switchable glass application of conducting organic-inorganic hybrid carbazole polymer. J. Electrochem. Soc. 2016, 163, H679-H683. [CrossRef]

37. Chang, K.H.; Wang, H.P.; Wu, T.Y.; Sun, I.W. Optical and electrochromic characterizations of four 2,5-dithienylpyrrole-based conducting polymer films. Electrochim. Acta 2014, 119, 225-235. [CrossRef]

38. Wu, T.Y.; Su, Y.S. Electrochemical synthesis and characterization of a 1,4-benzodioxan-based electrochromic polymer and its application in electrochromic devices. J. Electrochem. Soc. 2015, 162, G103-G112. [CrossRef]

39. Camurlu, P.; Gültekin, C. A comprehensive study on utilization of N-substituted poly(2,5-dithienylpyrrole) derivatives in electrochromic devices. Sol. Energy Mater. Sol. Cells 2012, 107, 142-147. [CrossRef]

40. Kuo, C.W.; Wu, T.L.; Lin, Y.C.; Chang, J.K.; Chen, H.R.; Wu, T.Y. Copolymers based on 1,3-bis(carbazol-9-yl)benzene and three 3,4-ethylenedioxythiophene derivatives as potential anodically coloring copolymers in high-contrast electrochromic devices. Polymers 2016, 8, 368. [CrossRef]

(c) 2017 by the authors. Licensee MDPI, Basel, Switzerland. This article is an open access article distributed under the terms and conditions of the Creative Commons Attribution (CC BY) license (http:/ / creativecommons.org/licenses/by/4.0/). 